\title{
Consumer Panic in the COVID-19 Pandemic
}

\author{
Michael Keane ${ }^{\dagger}$ AND Timothy NeAL ${ }^{\dagger}$ \\ ${ }^{\dagger}$ University of New South Wales $\& 3$ CEPAR, Sydney, NSW 2000 \\ E-mail: m.keane@unsw.edu.au \\ E-mail: timothy.neal@unsw.edu.au
}

\begin{abstract}
Summary We develop an econometric model of consumer panic (or panic buying) during the COVID-19 pandemic. Using Google search data on relevant keywords, we construct a daily index of consumer panic for 54 countries from January to late April 2020. We also assemble data on government policy announcements and daily COVID19 cases for all countries. Our panic index reveals widespread consumer panic in most countries, primarily during March, but with significant variation in the timing and severity of panic between countries. Our model implies that both domestic and world virus transmission contribute significantly to consumer panic. But government policy is also important: Internal movement restrictions - whether announced by domestic or foreign governments - generate substantial short run panic that largely vanishes in a week to ten days. Internal movement restrictions announced early in the pandemic generated more panic than those announced later. In contrast, travel restrictions and stimulus announcements had little impact on consumer panic.
\end{abstract}

JEL: C23, C51, D12, M31

Keywords: Coronavirus, Hoarding, Consumption, Panel Data, Containment Policy

\section{INTRODUCTION}

In this paper we present a model of consumer panic during the COVID-19 pandemic. Panic buying of storable consumer goods is a common phenomenon during natural disasters and man-made crises. Examples include both World Wars (Hughes 1988), the Great East Japan Earthquake in 2011, ${ }^{1}$ and the recent hyperinflation in Zimbabwe (Musvanhiri 2017). Panic may be provoked by much less, such as in the United States in 1973 when Johnny Carson joked about a shortage of toilet paper on The Tonight Show, causing the Great Toilet Paper Scare that led to panic buying and actual shortages (Malcolm 1974). Thus, is not surprising that the COVID-19 pandemic has caused consumers in many countries to engage in panic buying of storable consumer goods like toilet paper, rice and pasta - see e.g. Knoll (2020) and Rieder (2020). In this paper we develop a predictive model of how government policies such as social distancing, lockdowns and travel restrictions, as well as growth in COVID-19 cases, generate such behavior.

To clarify the discussion, it is necessary to define what we mean by "panic buying." First, we need to understand why consumers hold inventories of storable consumer goods in normal times. Erdem, Imai, and Keane (2003) - henceforth EIK - estimated a structural model of optimal consumer demand for storable goods in a stationary environment. In a stationary environment, consumers have two motives for building up inventories of storable goods in excess of current consumption needs: (i) as a buffer stock to protect

\footnotetext{
${ }^{1}$ See Hori and Iwamoto (2014), Ishida et al. (2013), and Kurihara et al. (2012) for research into the consumer reaction to the earthquake.
} 
against stock outs given uncertainty about future usage needs, and (ii) because it is optimal to stock up on storable goods when confronted with a "deal" (i.e., an instance when the good is offered by retailers at a relatively low price).

In the event of natural disasters or crises, however, consumers are commonly observed to stock up on consumer goods to an extent that greatly exceeds levels observed in normal times. During the COVID-19 pandemic, IRI (2020) document a sharp spike in grocery spending, and increases in stockpiling, in several countries. For example, for the week ending March 15, spending on paper products (including toilet paper) was up 50\% (year-on-year) in Italy, 108\% in France, 109\% in Germany, 134\% in the UK, and $217 \%$ in the US. There are both psychological and economic explanations for such stockpiling behavior in a crisis. For example, a standard psychological explanation is that stocking up on storable goods helps consumers gain a sense of control over the uncertain/risky situation created by a crisis (e.g. Grohol 2020).

On the other hand, as noted by Hansman et al. (2020), there is nothing intrinsically irrational or "panicky" about stocking up on storable consumer goods in a crisis. There are two main economic explanations for a jump in optimal inventory holdings in a crisis situation. First, in the EIK inventory model, any potential supply disruption that increases stock out risk, or any restriction on movement that increases the cost of store visits, will have the effect of increasing optimal inventory holdings. ${ }^{2}$ Second, as emphasized by Hansman et al. (2020), a crisis often leads to higher expected future prices, making the current price look like a "deal" that calls for stocking up. ${ }^{3}$ Again, this is optimal behavior in an inventory model.

Our primary goal in this paper is to develop a predictive model of how government policies impact on panic buying, so we do not need to take a stand on the extent to which the phenomenon is driven by psychological or economic factors. Regardless of the underlying cause, the phenomenon of panic buying is socially costly for several reasons. A sudden crisis induced jump in consumer demand above expected historical levels may often lead to retail store stocks outs in the short run. This is especially true in the case of just-in-time supply chains where little inventory is available to handle sudden jumps in demand. During the COVID-19 pandemic, serious stock out situations have been observed in many countries for consumer staples like toilet paper, rice and pasta. Such retail stocks outs are costly for consumers who are unable to obtain enough of the desired product to meet their usage needs, and particularly costly for vulnerable groups like the elderly and the disabled for whom shopping can be challenging.

Shortages created by panic buying also force consumers to devote extra time and effort to shopping, diverting time away from welfare-improving activities like work, leisure, and sleep, as well as generating psychological costs by inducing anxiety and stress. Shortages may heighten anxiety about the pandemic - and the government's response - among

\footnotetext{
2 In the EIK inventory model the cost of a store visit and the stock-out risk are two key parameters that drive optimal inventory holdings: Optimal inventory is increasing in the cost of a store visit (i.e., if store visits were costless, one could buy consumer goods on a just-in-time basis, keeping inventories near zero). The COVID-19 pandemic increased the cost of a store visit in three ways: (i) One may wish to avoid stores to avoid contact with potentially infected customers, (ii) if a consumer becomes infected they must quarantine at home, making store visits impossible for a time, (iii) government policies like lockdowns may make going to the store more difficult. Optimal inventory is also increasing in the risk of stock outs. If a crisis raises stock-out risk - either due to supply disruptions or due to a lagged response of supply to the crisis-induced increase in demand - it also leads to higher optimal inventory.

${ }^{3}$ The expectation of future price increases may even lead to speculative buying, where some people attempt to buy up inventory for subsequent resale at a higher price.
} 
the general population. Furthermore, as stressed by Hansman et al. (2020), reputable retailers avoid price increases during crises, both due to legal constraints and long run reputational concerns. This can lead to speculative buying and the emergence of black markets. Moreover, consumer panic may directly promote virus transmission, by causing people to flock to the supermarket before the onset of a lockdown.

We develop a measure of consumer panic for 54 countries over the first four months of 2020 using Google search data. The measure shows that consumers in most of the large economies of the world experienced panic in response to the COVID-19 pandemic. Much of the panic occurring in March, consistent with IRI (2020) data showing sharp increases in March grocery sales. We find strong heterogeneity in the timing and severity of consumer panic across countries in the sample. Some countries experienced more panic than others (such as Australia and the United States), and some panicked earlier while others much later. Generally speaking, panic appeared earlier in the Asian region than the rest of the world, and richer countries tended to panic more than poorer ones.

Given that consumer panic is a common response to crises and socially costly, it is useful to consider how government policy may contribute to - or alleviate - the phenomenon. Government policy as it relates to COVID-19 has focused on either the containment of viral transmission or efforts to prop up the economy. To that end, we construct three daily measures of government policy during the pandemic: 'internal restrictions' which curtail the freedom of movement and association within a city or greater region, 'travel restrictions' which limit or prevent people from entering the country, and 'stimulus announcements' which are announcements of a significant fiscal or monetary policy measures. The measures show that the majority of policy change occurred between the 13th and 24th of March, which is around the time that many of the world governments learnt that COVID-19 would severely affect their country.

There is substantial heterogeneity across countries in the timing, severity, and incrementalism of the policy response. Some countries, such as Brazil and South Korea, did not impose severe restrictions on movement, while others such as Spain and Peru imposed strict lockdowns. Countries such as Italy and Norway imposed internal restrictions 'early' (relative to other countries), while others like Singapore, Mexico and India imposed restrictions quite late. Some countries such as the United States and Canada allowed states/provinces to gradually implement restrictions (or not), while many others such as France and Argentina announced lockdowns at the federal level.

Using this data, we investigate a number of interesting questions related to consumer panic during the COVID-19 pandemic. For instance, why did some countries panic more than others, and why did some countries panic earlier and others later? One possibility is that differences in the extent and timing of the spread of COVID-19 explain differences in consumer panic. But heterogeneity in the severity and timing of government policy to contain the virus may also play a role. With many countries experiencing outbreaks of COVID-19 simultaneously, it is worth considering whether panic is driven primarily by policy change and virus transmission at the domestic level, or if consumers respond to events in other countries as well? (Perhaps because they serve as a signal of what is likely to occur in their own country.) If the activity of other countries also drive panic, does the impact of domestic policy announcements depend on what other countries have done? - i.e. does it matter for panic if governments implement lockdowns early or late relative to other countries?

If government policy has an impact on consumer panic, and if that impact is context dependent, then we need to learn these lessons so that it can factor into the decision

() 2020 
making of policymakers during the next pandemic/crisis, or even during subsequent waves or strains of COVID-19. To address this issue, we develop a dynamic model of panic as a function of policy change and the spread of COVID-19. It features domestic policy changes, the average change of policy in other countries, a nonlinear specification of domestic and overseas COVID-19 case increases, and interaction terms that allow for the effect of domestic policy changes to vary by the average state of policy overseas.

We find evidence for several conclusions about the spread of consumer panic during the COVID-19 pandemic: First, the announcement of internal movement restrictions clearly generates increased consumer panic, and the magnitude of the effect is large. This is in contrast to travel restrictions and stimulus announcements, where we find no evidence that either systematically leads to higher consumer panic. Second, consumers are also sensitive to the announcement of internal restrictions overseas, which explains why panic surged in some countries prior to domestic policy change. We also find strong evidence that the context of policy announcement matters: if the policy is announced early (relative to other countries) it has more of an effect on panic than policy announced later. The last conclusion of note is that the spread of the virus matters significantly too, although only if it is entered in the specification nonlinearly.

One policy implication of these results is that implementation of internal movement restrictions can be expected to induce panic buying in the short-run, particularly if the policy is announced before similar measures in other countries. The data suggests that the panic response is sudden, strong, and dissipates in a week to ten days. As the main objective of implementing internal movement restrictions is to contain virus transmission, early implementation of such a policy may still be optimal despite negative short-run consequences. ${ }^{4}$ Nevertheless, the speed of the panic response suggests that measures to prevent shortages in the face of consumer panic, such as rationing or priority access for vulnerable groups to essential goods, need to be implemented prior to (or simultaneously with) the announcement of policy change and not after the fact.

The second policy implication is that the announcement of strong travel restrictions appears to have very little effect on consumer panic. Thus, presuming travel restrictions are effective in suppressing virus transmission, implementing them early would appear to have been a very good policy strategy for governments in the current pandemic. Unlike internal restrictions, there is also no benefit in waiting to implement them. Further research is needed on the effects of policy change on unemployment and virus transmission to determine the optimal policy mix that balances the desire to suppress virus transmission with minimizing economic disruption and consumer panic. ${ }^{5}$

The outline of the paper is as follows. Section 2 describes how we construct measures of panic and government policy during the COVID-19 pandemic, and describes key features of the data. Section 3 describes the econometric methods we use to model consumer panic. Section 4 presents our estimation results, including impulse response functions for policy changes. Section 5 draws conclusions from the analysis, while the Appendix contains supplementary information and results.

\footnotetext{
${ }^{4}$ Since virus transmission leads to higher consumer panic as well, the early implementation of the policy could even be optimal in regards to the minimization of consumer panic over the long term.

${ }^{5}$ Chinazzi et al. (2020) study the effect of travel restrictions on virus transmission, while Fang et al. (2020) study the effect of internal movement restrictions. The former paper argues that travel restrictions have only modest effects unless combined with transmission-reduction interventions (e.g., internal movement restrictions)
} 


\section{MEASURING PANIC AND POLICY DURING THE COVID-19 PANDEMIC}

\subsection{Measuring Consumer Panic}

A good measure of consumer panic must satisfy several criteria. Panic by its very nature is subject to sudden daily changes. The factors that drive panic - government policy and virus transmission - have also been subject to sudden changes during the pandemic. Thus, to model the dynamics of the panic process, we need a daily measure of consumer panic. The COVID-19 pandemic is a very recent event that has just reached its fifth month, so we also need a measure of panic that is available as close to the present day as possible. Lastly, we require a measure that is available for many countries, in order to exploit heterogeneity in virus transmission and policy response. While supermarket scanner data on grocery sales is available on a daily basis, it is not available for many of the countries we wish to include in the analysis. Accordingly, in this article we construct a high frequency measure of consumer panic using Google search data.

Google search data was shown by Choi and Varian (2012) to be useful in "now-casting" current values of economic indicators such as unemployment claims and consumer confidence. Da et al. (2011) use Google search data to obtain a useful measure of investor attention that predicts demand for stocks, while Goel et al. (2010) demonstrate that present search activity on Google can be useful in predicting near-future consumer behavior. ${ }^{6}$ Underlying all of this research is the idea that Google search data is a useful indicator of consumer demand. Using Google search data to measure the degree of consumer panic in an economy is a simple extension of this idea, and it allows us to capture sudden surges in panic as they occur across the world in reaction to the virus.

The Google Health Trends API provides data on the proportion of searches undertaken on their search engine within a jurisdiction and time period matching any specified word or phrase. For example, for the word 'panic', the API will return the probability that a short search-session, which is defined as a few consecutive searches by a single user, includes a search for 'panic' within a particular jurisdiction during a day. The data is provided in the form of a probability, thus adjusting for differences in population and Google usage between countries. The numbers are obtained from a uniformly distributed random sample of Google web searches, and are available for daily search activity (using the UTC timezone) in most countries of the world.

To construct an index of panic during the COVID-19 pandemic, we use a set of keywords or phrases that attempt to track a sudden proclivity for abnormal patterns of consumer behavior indicative of 'panic buying.' It is crucial to not only find words that people in English-speaking countries are likely to search, but also ones that can be translated into many other languages and receive search activity across the globe. We collected data for the following seven words or phrases: 'toilet paper', 'panic buying', 'hoarding', 'panic', 'supermarket', 'recession', and 'unemployment' (and their translations). ${ }^{7}$

Only the term 'toilet paper' relates to a specific good, while the remainder track search interest in specific concepts. Of course, there are other products that experienced a surge in demand following the onset of the pandemic, including face masks and hand

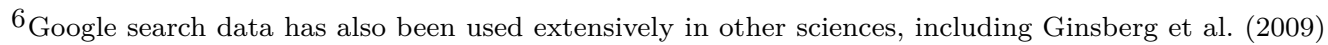
who use it to predict outbreaks of influenza. And most recently, Lampos et al. (2020) use it to estimate underlying numbers of COVID-19 cases in a country.

${ }^{7}$ For privacy reasons Google censor the probability of a search term if it did not get enough distinct searches. A country must have enough Google searches for each keyword for its data to be usable.
} 
sanitizer. We choose not to include these products as their utility arguably increases dramatically during a pandemic, and a surge in demand could be seen as a perceived need for immediate use. Toilet paper, on the other hand, does not provide more utility during this pandemic as Diarrhoea is a very rare symptom of COVID-19. Any increase in demand for toilet paper is therefore due to reasons other than immediate use.

Our index for panic is the sum of the probabilities of the first five terms:

$P_{c t}=\left(\right.$ ToiletPaper $_{c t}+$ PanicBuying $_{c t}+$ Hoarding $_{c t}+$ Panic $_{c t}+$ Supermarket $\left._{c t}\right) * 100$

where ToiletPaper Tt $_{\text {is }}$ the search probability for that keyword in country $c$ on day $t$, and likewise for the other search terms. Probabilities of individual search terms are inherently small, so the sum is multiplied by 100 to make it more readable. We also consider an extended version of the panic index that incorporates a fear of economic insecurity by adding the terms 'recession' and 'unemployment' to the sum (see Section 4.5).

For countries that are not majority English-speaking, we translated these terms into 23 languages in consultation with native speaking colleagues. If a country has a non-trivial number of speakers of a certain language, we add the search probabilities of the translated term to the probability of the English term. For instance, in the case of Switzerland, we add the German, French, and Italian translations to the English search probabilities. Example translations can be found in Table 7 in the Appendix.

The result is a balanced panel dataset that contains 54 countries $(N=54)$, including all of the major economies in the world save for Mainland China, ${ }^{8}$ and daily measures of panic from the 1st of January this year to the 27 th of April $(T=118){ }^{9}$

Figure 1 plots the panic index against global COVID-19 cases in log scale. For the purpose of illustration, we group the countries into three regions: Europe and North America, Asia (including Oceania), and the Rest of the World, which includes Southern and Central America, Africa, and the Middle East. The first panic occurred in Singapore and Taiwan from February 6th to 10th, which increased the panic index for Asia to double its normal level (i.e., from about .04 to about .08). During this time COVID-19 cases in China climbed from 20,000 to over 40,000, and cases were starting to spread in other East Asian countries. Panic quickly returned to normal levels in Asia until February 28th, when it surged to an average of 0.14 and remained high during the first week of March. By this point COVID-19 cases in China had plateaued above 80,000, but cases outside China were growing very quickly. This was particularly true in Italy, who over this period grew from 650 confirmed cases to 6,000 .

It wasn't until the 11th of March that North America and Europe began to experience high levels of panic, with the index increasing from about 0.05 to a peak of almost triple that amount at 0.14. Consistent with this, the IRI (2020) supermarket sales data show a massive spike in demand for paper products in the week ending March 15. It was in the first week of March that many governments around the world began to appreciate that COVID-19 would severely affect their country. In the second and third weeks of March,

\footnotetext{
${ }^{8}$ We cannot include Mainland China as the government restricts the use of the Google search engine.

${ }^{9}$ The complete list of countries/jurisdictions in the dataset are as follows: Argentina, Australia, Austria, Belgium, Bolivia, Brazil, Canada, Chile, Colombia, Denmark, the Dominican Republic, Ecuador, Egypt, Finland, France, Germany, Greece, Guatemala, Hong Kong SAR, India, Iran, Ireland, Italy, Japan, Kenya, Malaysia, Mexico, Morocco, the Netherlands, New Zealand, Norway, Panama, Peru, the Philippines, Poland, Portugal, Qatar, Romania, Russia, Saudi Arabia, Singapore, South Africa, South Korea, Spain, Sweden, Switzerland, Taiwan, Thailand, Turkey, the United Arab Emirates, the United Kingdom, the United States, Uruguay, and Vietnam.
} 
Figure 1. Average Panic and Worldwide Cases of COVID-19

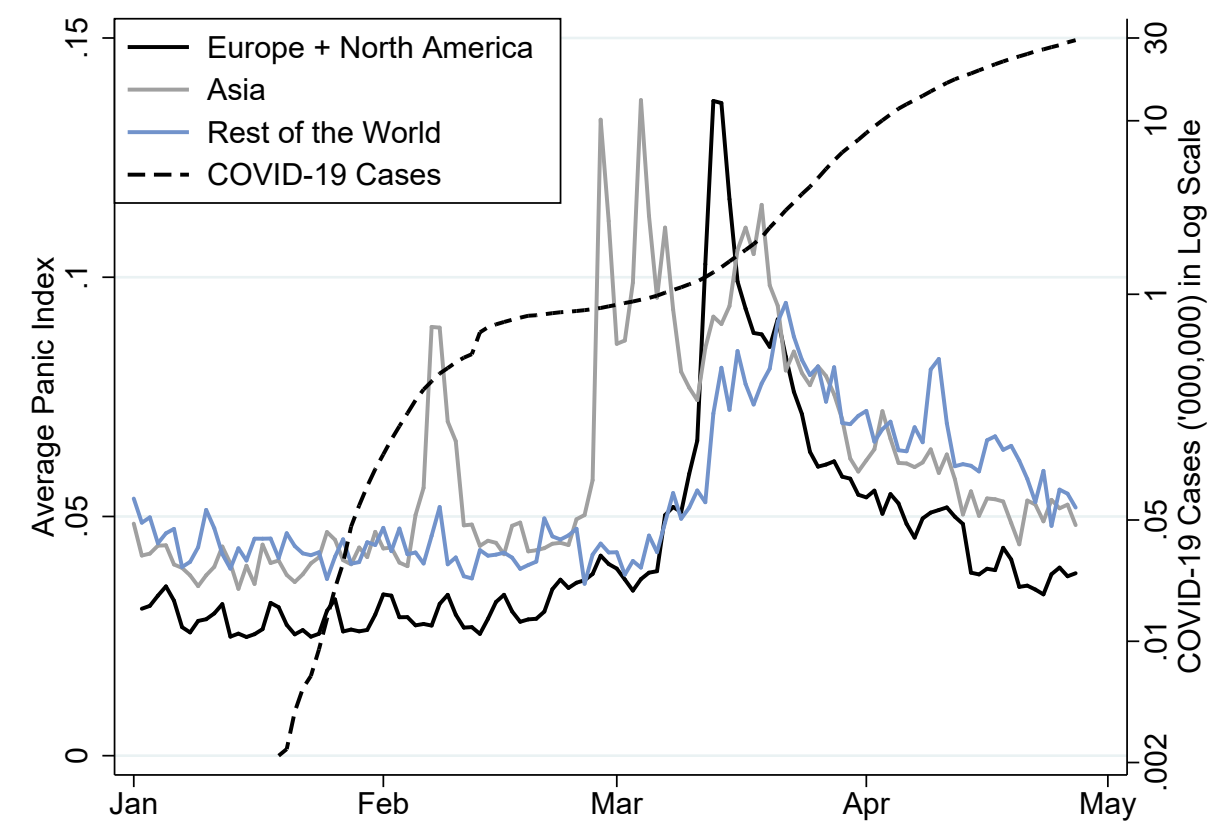

Note: This figure plots the average panic across North America and European Countries, Asian countries (including Oceania), and the Rest of the World which includes Southern and Central America, Africa, and the Middle East. Also presented in log scale is the global confirmed cases of COVID-19 on the secondary y-axis.

reported COVID-19 cases were growing exponentially in many countries of the world, and unprecedented legislation was being announced in attempts to contain the spread of the virus. The remainder of the countries in the sample, which include Central and South America, Africa, and the Middle East, also experienced a surge in panic in the middle of March. By April, the panic index subsided as people adapted to a new normal and fears of imminent food shortages subsided in most advanced economies.

Figure 1 shows significant heterogeneity between regions in the timing and severity of the panic over the past four months. There was also significant heterogeneity across countries within regions. ${ }^{10}$ This leads to the question of why some countries panicked much more than other countries, and why some countries panicked earlier and others later. The differential spread of COVID-19 across countries, and their diverse range of policy responses, provide an excellent opportunity to study how different factors drive the spread of consumer panic.

Table 1 presents descriptive statistics of the individual search terms and the overall panic index. Among the five search terms present in the panic index $P_{c t}$, 'Supermarket' is the most often searched term, followed by 'panic' and then 'toilet paper.' Looking at the coefficient of variation, 'toilet paper' has the most variability of all the search terms, due to its very small probability of being searched in normal times and very large spikes during the COVID-19 pandemic. It is followed by 'unemployment' which will be included in our alternative extended panic index.

\footnotetext{
${ }^{10}$ An Appendix with graphs of the panic index for every country is available on request. 
Keane \& Neal

Table 1. Descriptive Statistics of Google Trends Keywords and Panic Index

\begin{tabular}{lcccc}
\hline \hline & & & & \\
& & & & \\
& & & & \\
& & & & \\
Keyword Searches: & & & & \\
Toilet Paper & 0.008 & 0.003 & 0.027 & 3.320 \\
Panic & 0.010 & 0.007 & 0.011 & 1.150 \\
Panic Buying & 0.002 & 0.000 & 0.005 & 2.591 \\
Hoarding & 0.002 & 0.001 & 0.003 & 1.573 \\
Supermarket & 0.027 & 0.018 & 0.028 & 1.012 \\
Recession & 0.005 & 0.002 & 0.012 & 2.339 \\
Unemployment & 0.014 & 0.006 & 0.045 & 3.194 \\
& & & & \\
Panic Index & 0.049 & 0.039 & 0.044 & 0.894 \\
& & & & \\
\hline Note: CV refers to the Coefficient of Variation.
\end{tabular}

\subsection{Measuring Government Policy}

A remarkable effect of the pandemic has been the dramatic response from governments: Drastic changes to the functioning of society have often been formulated in under a week and announced only one or a few days before implementation. Government policy has focused on containment of viral transmission, along with fiscal and monetary policy devised to prop up the economy while containment measures are given time to work. As our outcome of interest is panic, which as we have seen is subject to high frequency changes, it is important to track the evolution of government policy in a precise manner that captures the timing of any sudden changes. Because of this we measure policy changes at their announcement rather than at their implementation.

We categorize policy announcements into three broad types: (1) 'internal restrictions' which curtail freedom of movement and association within a city or greater region, (2) 'travel restrictions' which limit or prevent people from entering the country, and (3) 'stimulus announcements' which are changes in fiscal or monetary policy. We now discuss how we code the policy announcement variables, recognizing that this must involve some degree of subjectivity:

The index for 'internal restrictions' is defined as follows:

$$
\text { Internal }_{c t}=\text { Schools }_{c t}+\text { Gatherings }_{c t}+\text { Movement }_{c t}
$$

where $S$ chools $s_{c t}=1$ if there is a federal closure of primary and secondary schools in coun$\operatorname{try} c$ on day $t$, and 0 otherwise. Gathering $s_{c t}=1$ if there is a ban on very large gatherings (more than 500 to 2000 people), 2 if there is also a ban on smaller gatherings (more than 50 to 200 people), and 0 otherwise. Movement st $_{c}=1$ if the government strongly encourages work from home where feasible, there are heavy restrictions on the use of public spaces, and most retail and entertainment businesses are closed. Movement $_{c t}=2$ if, in addition to the above, many non-essential industries are shut down and a majority of individuals are prevented from working, and 0 otherwise. Occasionally a half point will be assigned to a policy position when it is difficult to categorize (such as State governments adopting a policy but not the federal government). Internal ${ }_{c t}$ can range from 0 to 5 . 
The index for 'travel restrictions' is defined as follows:

$$
\begin{aligned}
\text { Travel }_{c t}= & \left(\text { ChinaBan }_{c t}+\text { IranBan }_{c t}+\text { ItalyBan }_{c t}+\text { SouthKoreaBan }_{c t}\right) / 2 \\
& + \text { Noncitizens }_{c t}+\text { Citizens }_{c t}
\end{aligned}
$$

where ChinaBan Cht $_{1}=1$ if all travellers arriving from China must self-isolate for 14 days, 2 if all travellers from China are banned from entering the country, and 0 otherwise. Likewise for $\operatorname{IranBan}_{c t}$, ItalyBan It $_{\text {, }}$, and SouthKoreaBan , $_{\text {, }}$, which were chosen along with China as they were the four countries to be most affected from COVID-19 early in the Pandemic. Noncitizens $s_{c t}=1$ if non-citizens arriving in the country must self-isolate for 14 days, 2 if non-citizens are banned from entering the country, and 0 otherwise. Likewise, Citizens $_{c t}=1$ if all citizen entrants must self-isolate for 14 days, 2 if citizens are effectively prevented from entering the country, and 0 otherwise. ${ }^{11}$

Lastly, the variable for stimulus announcements Stimulus $s_{c t}$ is the sum of all government policy announcements that signal significant changes in fiscal or monetary policy. We collected these from an array of media websites.

Figure 2. Average Policy and COVID19 Cases by Region

Avg. Internal Restrictions

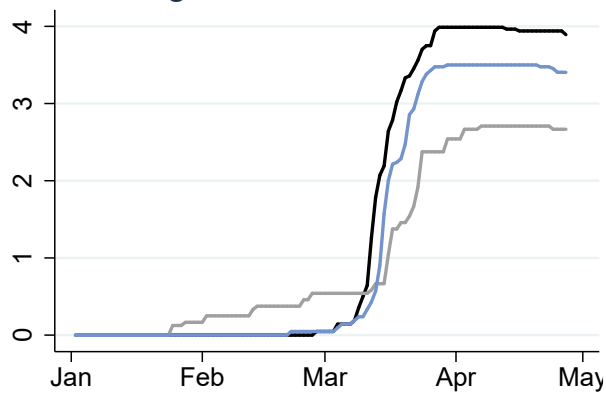

Avg. Stimulus Announcements

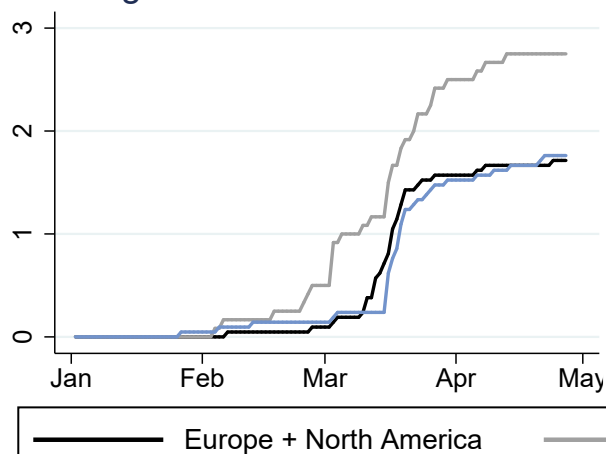

Avg. Travel Restrictions

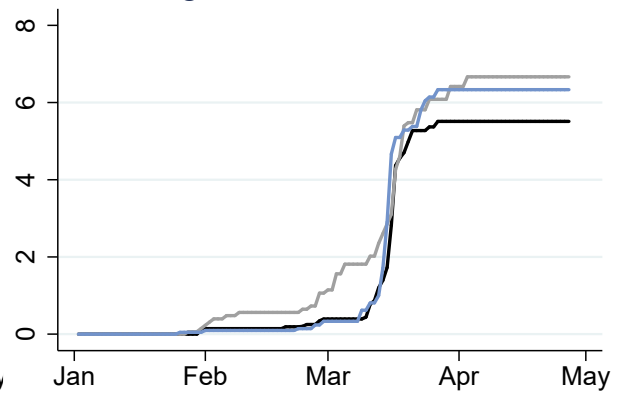

Avg. LN(COVID-19 Cases)

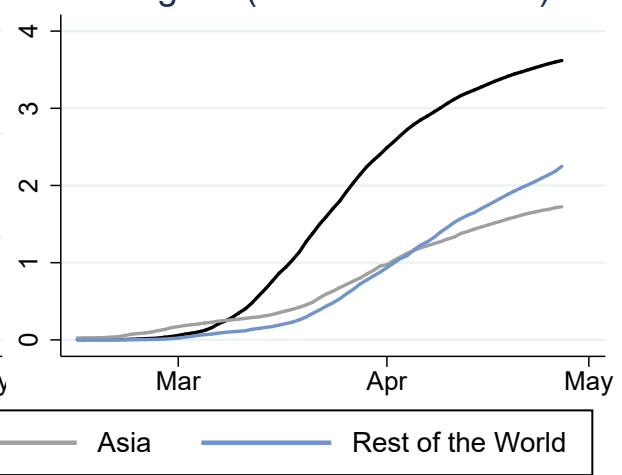

Note: This figure plots the average value of the three policy variables constructed in this article and log of COVID-19 cases across three regions in the sample of 54 countries.

11 As far as we know, no countries in the sample officially stated that its own citizens were not allowed to re-enter the country, but there were several instances when borders were so tightly closed it was virtually impossible for citizens to obtain transport back into the country. 
Figure 2 describes the evolution of our three policy measures over the sample period and across 54 countries, measured as a simple average across the three regions defined above. Looking at internal restrictions in the top-left panel, it is clear that most policy change occurs between the 13th and 24th of March, when the average index increased from one to over three. Europe and North America behave similarly to the rest of the world, while the Asian countries imposed some internal restrictions much earlier but settled at a lower average level. Travel Restrictions behave similarly, with many countries in the sample completely closing their borders around mid-March, and Asian and Oceanic countries again implementing policy change sooner than the other regions. The Asian region adopted an incrementalist approach to Stimulus announcements of frequent announcements of small policy changes, while the other regions tended to announce large stimulus packages in Mid-March.

Figure 3. The Timing of Policy Announcements
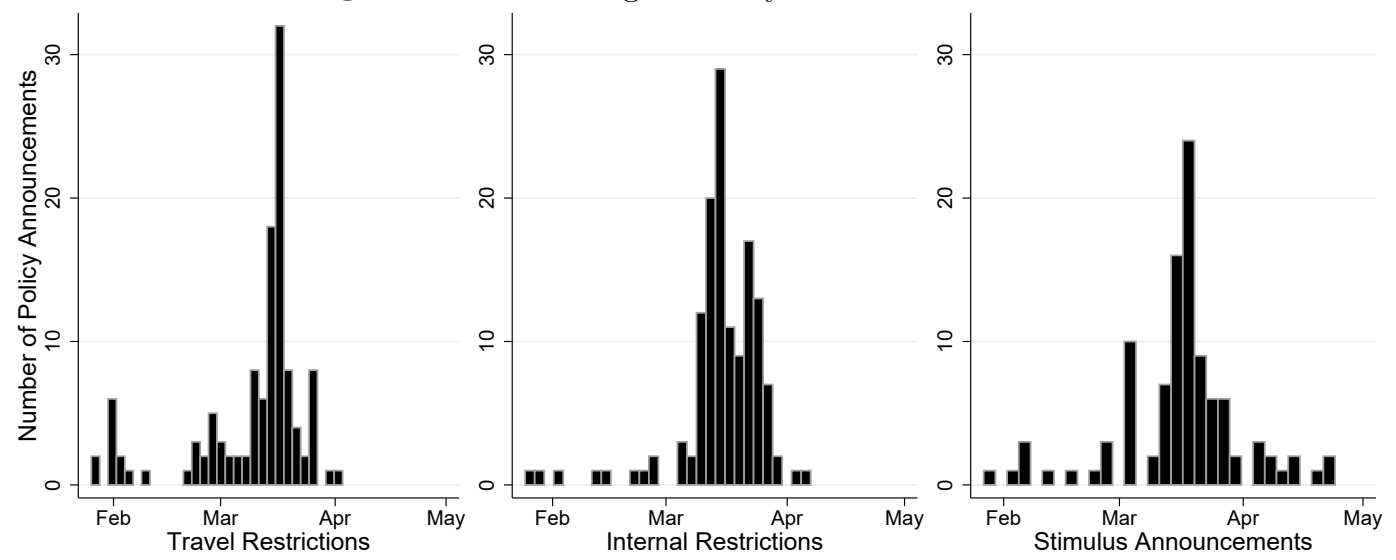

Note: This figure graphs the distribution of new policy announcements by date across the three categories.

The above discussion masks significant heterogeneity in policy within regions. Figure 3 plots the number of policy announcements made in each category between February and May. The peak of the distribution sits firmly within early-to-mid March, for internal restrictions, and the middle of March for travel restrictions. Nevertheless, more than a few internal restriction announcements were made in early and late March (with some even in early April and February). And for travel restrictions there were a number of countries such as Australia and New Zealand who were gradually ramping up entrant restrictions throughout the end of January to early March.

It is worth considering whether countries that announced strong containment policies earlier than most others, which we'll call the 'early countries,' had different consumer panic patterns than those who announced their policies late, which we'll call the 'late countries.' Figure 4 considers average internal restrictions and average panic across seven notably early countries and seven notably late countries. The early countries had moved to tight internal restrictions by early March, and average panic seems to track the policy index very closely for these countries until the panic decays in late March and April. The late countries had a very different experience, where tight restrictions on movement did not occur until late in March. In the late countries panic peaks well prior to the 
Figure 4. Average Panic and Internal Restrictions by Group

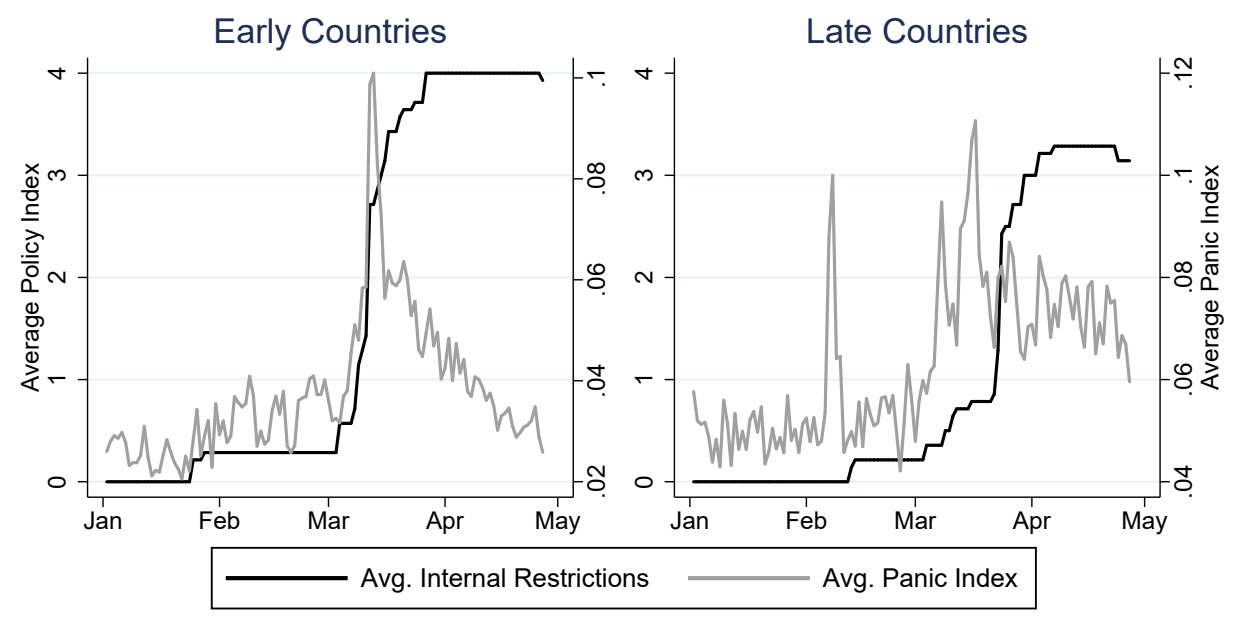

Note: 'Early Countries' include Austria, Belgium, Ireland, Italy, Hong Kong, Norway, and Romania. 'Late Countries' include India, Mexico, Qatar, Singapore, Sweden, the United Arab Emirates, and Vietnam.

implementation of tight policy measures, and panic also dissipates much more slowly. This suggests two hypotheses about the relationship between internal restrictions and panic: First, that individuals in a country not only react to domestic policy change but also overseas policy change. Second, that the effect of announcing internal restrictions on panic may depend crucially on the international context in which it is announced, with late implementation leading to less consumer panic in the short-run.

Finally, Figure 5 presents the experience of four countries in detail: Italy, the United Kingdom, France, and Australia. The subgraphs for each country feature the panic index from February to May, the daily increase in COVID-19 cases (in thousands), and announcements of internal and travel restrictions which are shaded in two colors.

In Italy there was a brief spike in panic on Feb. 23-24, around the time that outbreaks were reported in northern Italy and several governors imposed interstate travel restrictions. The real surge in panic began in the second week of March, and it continued to climb until March 22, when our panic index peaked at three times its normal level. In early March the government began implementing restrictions on medium and large sized gatherings, including restrictions on movement in the worst affected parts of the country. On March 20 a nationwide lockdown was announced, and soon after that panic reached its peak of 0.15 . Since then, panic has trended down in a way entirely consistent with declines in the number of new cases per day from about 6,000 to about 2,000.

France offers an interesting comparison as the panic surges and subsides much quicker than in Italy, akin to the rapid speed in which containment policy escalates. A nationwide lockdown was announced in France on the 16th of March, which is the same day that panic reaches its peak of 0.083. Comparing the trends in daily COVID-19 cases, it's also clear France implemented its lockdown sooner in the life of viral transmission.

In the United Kingdom panic peaks roughly the same time as in Italy even though the virus started spreading much later. The peak of panic occurs simultaneously with the announcement of internal restrictions, with a school closing announcement on the 18th of March and restrictions on gatherings and movement being announced on the 20th and 
Figure 5. Panic, COVID-19, and Government Policy in Select Countries

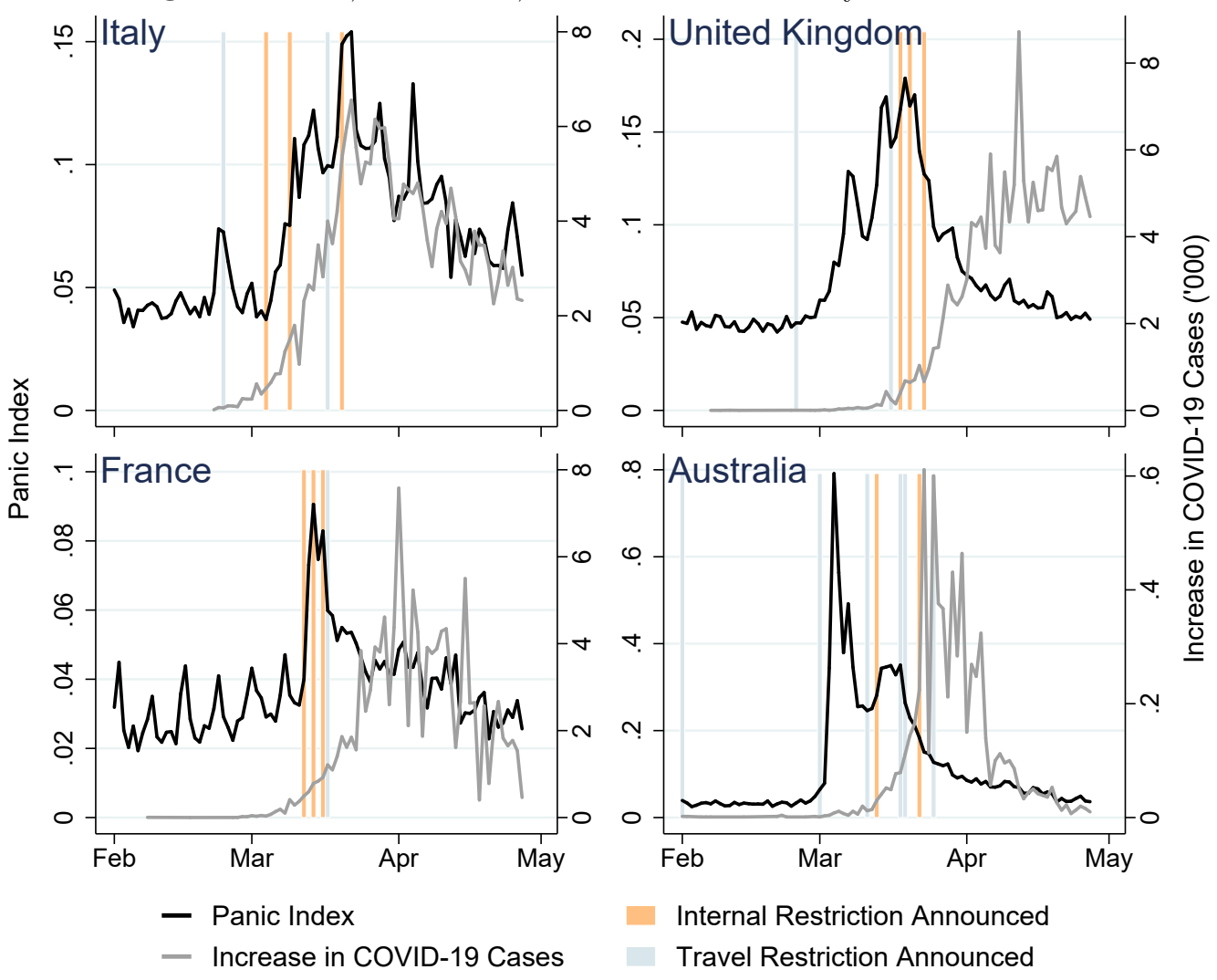

the 23rd of March. Unlike Italy and France, the number of new COVID-19 cases has not declined by the end of the sample period.

The experience of Australia is notable for the incredible speed and scale with which panic took hold in early March. On March 2nd the panic index was at 0.08, already double its typical level. Two days later it increased to 0.79 , which is exceeded only by a value of 1.03 in Japan on Feb. 28th. Unlike in other countries, the escalation in panic does not appear to correspond with any significant increase in domestic COVID-19 cases. Indeed, it is important to note that axes in Figure 5 are scaled differently for Australia: It has an order of magnitude higher peak panic index and lower peak caseload than the other three countries! Nor does any important policy announcement seem to explain the panic: While a travel ban from Iran was announced on the 1st of March, it seems unlikely that this was important enough to be the direct cause. Restrictions on gatherings were announced on March 13th, along with a series of escalating travel restrictions, which coincides with a secondary minor peak in the middle of March.

Looking at these four examples, we see a great deal of heterogeneity in the timing and severity of consumer panic, the timing of COVID-19 transmission across countries, and finally the timing and severity of containment policy. It would be exceedingly difficult to make conclusions on the likely causes of panic surges without a multivariate statistical model of panic, to which we now turn. 


\section{METHODOLOGY}

\subsection{Conceptual Framework}

It is useful to first present a simple conceptual framework to motivate our empirical specification. To set ideas, let $P_{c t}$ denote the level of consumer panic for a typical consumer in country $c$ on day $t$ of the pandemic. Let $S_{c t}$ denote the severity of the pandemic, and let $R_{c t}$ denote the policy regime in place in country $c$ on day $t$. Then we may write:

$$
P_{c t}=F\left(E\left(S_{c t} \mid I_{c t}\right), E\left(S_{c t+1}, \ldots \mid I_{c t}\right), R_{i t}, E\left(R_{c t+1}, \ldots \mid I_{c t}\right), \mu_{c}\right)
$$

Here $E\left(S_{c t} \mid I_{c t}\right)$ denotes the perceived severity of the pandemic on day $t$, conditional on the available information set $I_{c t}$. Similarly, $E\left(S_{c t+1}, \ldots \mid I_{c t}\right)$ denotes the expected severity of the pandemic in future periods. $\mu_{c}$ is a range of country-specific factors that affect the propensity to panic (e.g., cultural factors, strength of the social safety net).

The information set has the form:

$$
I_{c t}=\left(C_{c t}, C_{c, t-1}, \ldots, C_{f t}, C_{f, t-1}, \ldots, R_{c t}, R_{c, t-1}, \ldots, R_{f t}, R_{f, t-1}\right)
$$

where $C_{c t}$ denotes the COVID-19 caseload in country c on day $t$, and $C_{f t}$ denotes a vector of caseloads in foreign countries. Similarly, $R_{c t}$ denotes the policy regime in country c on day $t$, and $R_{f t}$ denotes a vector of policy regimes in foreign countries. Thus, the information set includes current and lagged caseloads both domestic and foreign, as well as current and lagged policies, both domestic and foreign.

In writing (3.3)-(3.4) we assume that consumers have incomplete information about the severity of the crisis, which seems obvious given that even epidemiologists have great uncertainty on the virulence and transmissibility of COVID-19 at this stage of the pandemic. We assume consumers use COVID-19 caseloads, both domestic and foreign, to infer the severity of the pandemic. Consumers also use government policy as a signal of the severity of the pandemic, under the reasonable assumption that governments and the experts they consult have information about the pandemic exceeding that of the typical consumer. $^{12}$

We may consider equation (3.3) the "structural" equation for consumer panic. The "reduced form" equation for consumer panic is obtained by substituting out for the unobserved expectation terms in (3.3) using the information set in (3.4) to obtain:

$$
P_{c t}=f\left(C_{c t}, C_{c, t-1}, \ldots, C_{f t}, C_{f, t-1}, \ldots, R_{c t}, R_{c, t-1}, \ldots, R_{f t}, R_{f, t-1}, \ldots, \mu_{c}\right)
$$

In this framework the policy regime $R_{c t}$ affects consumer panic through four channels. First, there is the direct effect of the policy. Second, there is the effect of the policy on expected future policy. Third, there is the effect operating through the impact of policy on the perceived current severity of the pandemic $E\left(S_{c t} \mid I_{c t}\right)$. Fourth, there is the impact of policy on the expected severity of the pandemic in the future $E\left(S_{c t+1}, \ldots \mid I_{c t}\right)$.

As a simple example, consider an internal movement restriction that makes it more difficult for consumers to leave home and visit the store. First, as discussed in the introduction, anything that raises the cost of store visits will cause consumers to desire

\footnotetext{
12 See Avery et al. (2020) for a discussion of alternative epidemiological models, as well the uncertainty about the inputs to those models. Their paper discusses how the caseload projections of the Imperial College model in Ferguson et al. (2020) significantly influenced several leading countries, such as the US and UK, to impose strict social distancing rules after an initial response that was more moderate.
} 
higher inventories. Thus, a new internal restriction may generate "panic" buying (i.e., heavy stockpiling) in the short run. Second, if the policy leads consumers to expect even tighter restrictions in the future, it will encourage even more demand today. Third, if consumers have incomplete information about the severity of the crisis and use government policy as a signal, it is plausible that a new internal movement restriction may cause panic by causing consumers to infer that the crisis is worse than previously thought. Fourth, stronger government action may increase confidence about the future course of the pandemic, reducing fears of future shortages. Through this channel, a new internal movement restriction may reduce consumer panic. ${ }^{13}$

The overall impact of any policy move on consumer panic will depend on the balance of these four forces. The first key point we wish to make is that this balance is likely to depend on the consumer information set, and in particular the time since the start of the crisis. Early in the pandemic, when there is a great deal of uncertainty about its severity, the third channel is likely to be very strong, so we would not be surprised if strong policy action induces consumer panic. Later in the crisis, when consumers have better information, we hypothesize that this third channel is weaker, so that policy actions will be less likely to induce panic.

The number of COVID-19 cases reported in foreign countries provide signals about the current and likely future severity of the pandemic in one's own country. Policy actions of foreign governments are also likely to be a key source of consumer information about the potential severity of the pandemic in their home country. They may also provide signals about the likely future policies one's own government will adopt. Thus, foreign government policies $R_{f t}$ and foreign caseloads $C_{f t}$ may also affect domestic panic through channels two through four described above.

A key issue we wish to address is whether the level of panic induced by domestic policy action depends on the timing of that action relative to other countries. We hypothesize that if a country acts early the second channel (i.e., policy action signals a more severe crisis) is likely to dominate, so that early strong policy actions will induce short run panic. We also hypothesize that if a country acts relatively late, then the severity of the pandemic will already be fairly well understood, so this signalling mechanism will be less strong. Thus, we expect later action to induce less consumer panic. To capture these type of effects, it is important that when we specify the reduced form model in (3.5) we allow the policy regime in foreign countries to moderate the impact of domestic policy.

\subsection{Reduced Form Model of Consumer Panic}

Guided by the above conceptual framework, we proceed to specify a reduced form model of consumer panic. A priori, we decided to model consumer panic as a dynamic process in which the level of panic in country $c$ on day $t$ depends on it's own lagged level, as well as changes in the forcing variables (i.e., domestic and foreign policy regimes, domestic and foreign cases) from day $t-1$ to day $t$. This was because we expected that changes in policy and COVID-19 cases would have strong short-run effects on panic, but that these

${ }^{13}$ The severity of the pandemic at time $t$ will be some function of past severity and past containment policy $S_{c t}=g\left(S_{c t-1}, R_{c t-1}\right)$. In Section 2.2 we defined the internal restriction policy measure $R_{c t}$ so larger values imply stricter constraints on movement. So it is reasonable to assume that $\partial S_{c t} / \partial R_{c t-1}<$ 0 . A similar assumption makes sense for travel restrictions. But in the case of stimulus announcements it is not clear why they would affect virus transmission, a point we return to when interpreting the results. 
effects would die off rather quickly. After some experimentation with functional form, we arrived at the following model as our main specification:

$$
\begin{aligned}
\ln P_{c t} & =\mu_{c}+\sum_{\ell=0}^{1}\left(\boldsymbol{\beta}_{\ell} \Delta \mathbf{R}_{c, t-\ell}+\gamma_{\ell} \Delta \mathbf{R}_{f, t-\ell}+\boldsymbol{\lambda}_{\ell}\left(\Delta \mathbf{R}_{c, t-\ell} * \mathbf{R}_{f, t-\ell}\right)\right) \\
& +\theta_{1} \Delta \ln C_{c t}+\theta_{2} \Delta C_{c t}+\theta_{3}\left(\Delta \ln C_{c t} \cdot \Delta C_{c t}\right)+\theta_{4} \Delta \ln C_{c t}^{*}+\theta_{5} \Delta C_{c t}^{*} \\
& +\theta_{6} \Delta \ln C_{f t}+\theta_{7} \Delta C_{f t}+\theta_{8} \Delta C_{C N, t}+\theta_{9} C_{C N, t} \cdot I_{c \in A s i a} \\
& +\sum_{\ell=1}^{2} \rho_{\ell} \ln P_{c, t-\ell}+\boldsymbol{\psi} \mathbf{d a y}_{t}+e_{c t}
\end{aligned}
$$

Here $\ln P_{c t}$ is the $\log$ of the panic index for country $c$ on day $t$, and the model includes two lags of the dependent variable. $\mathbf{R}_{c t}=\left[\right.$ Internal $_{c t}$, Travel $_{c t}$, Stimulus $\left._{c t}\right]$ is a vector of our three policy variables: Internal Restrictions, Travel Restrictions, and Stimulus Announcements. These enter the model in first difference form $\left(\Delta \mathbf{R}_{c t}\right)$ and we include both the current and first lagged daily difference. $\mathbf{R}_{f t}$ is a vector of the same three policy variables for foreign countries, measured as the simple average across countries outside of country $c .{ }^{14}$ We also enter this variable in first-differenced form, including one lag.

The term $\boldsymbol{\lambda}_{\ell}\left(\Delta \mathbf{R}_{c, t-\ell} * \mathbf{R}_{f, t-\ell}\right)$ allows the effect of domestic policy changes to vary depending on the international context in which they are announced, where the international context is captured by $\mathbf{R}_{f t}$, the average level of the policy variables in countries outside of $c$. If $\lambda_{p \ell}<0$ then the effect of announced changes in policy $\Delta \mathbf{R}_{c, t-\ell}$ on panic is reduced the more governments overseas have already announced that change in policy. We hypothesize that $\lambda_{p \ell}<0$ based on the discussion in Section 3.1.

We let changes in the number of confirmed COVID-19 cases enter the model in several different ways. First, we enter the daily percentage change in domestic cases, $\Delta \ln C_{c t}$, the daily absolute change in domestic cases, $\Delta C_{c t}$, and the product of these two terms. Early in the pandemic, when caseloads are low, large daily percentage increases are sometimes observed. Later in the pandemic, when caseloads are higher, the daily percentage changes are typically small, but the absolute changes can be large. We included both percentage and absolute changes, as well as their interaction, as this allows the model to be quite flexible in terms of how caseloads affect consumer panic.

Second, we were interested to see if surprise changes in caseloads had larger effects than predictable changes. To test this, we built predictive models for both percentage and absolute changes in caseloads, reported in Appendix A. We defined the surprise changes in caseloads as the residuals from these models. These are denoted by $\Delta \ln C_{c t}^{*}$ and $\Delta C_{c t}^{*}$ in equation (3.6). Third, we also allow foreign reported cases to influence domestic panic. We include both the daily percentage change in foreign cases, $\Delta \ln C_{f t}$, and the daily absolute change in foreign cases, $\Delta C_{f t}$.

Fourth, we cannot include mainland China directly in our model as it restricts access to Google. However, as the pandemic originated in China, we include the number of confirmed changes in mainland China as a driver of consumer panic in other countries $C_{C N, t}$. We also included an interaction between the number of Chinese cases and and

\footnotetext{
${ }^{14}$ We experimented with weighted averages based on criteria such as distance, GDP, population, and the incremental $R^{2}$ when panic in country $c$ is regressed on measures for each foreign country separately. But these refinements had little impact on the results.
} 
indicator for whether country $c$ is in East or Southeast Asia, to allow for the possibility that Chinese cases have a larger effect on consumers in nearby countries. Finally, day is a vector of day-of-the week dummies to capture daily differences in search activity.

The term $\mu_{c}$ is a country specific fixed effect meant to capture differences across countries in the baseline level of Google search activity for panic related terms. We estimate the model by fixed effects, relying on the fact that we have a long panel $(\mathrm{T}=116)$ so that the so-called Nickell (1981) bias that arises from applying a fixed effects estimator to a lagged dependent variable model in a panel with small $\mathrm{T}$ is rendered negligible.

We assume the error $e_{i t}$ satisfies usual assumptions: serially uncorrelated, homoskedastic, independent in the cross-section and independent from the regressors. We found evidence of conditional heteroskedasticity, and applied a weighted least squares procedure described below. Given this, we show in Section 4 that the model passes a stringent set of specification tests, so the testable assumptions on the errors are not rejected.

Before turning to the results, there are two additional details of the specification. First, to avoid having the log of the panic index be too sensitive to days with exceptionally low levels of search activity, we add .01 to the index before taking the log, so that we actually work with $\ln \left(P_{c t}+.01\right)$. The value .01 corresponds to roughly the first decile of the distribution of $P_{c t}$ across all countries and days in the sample (Recall from Table 1 that $P_{c t}$ has a mean of .049). Second, to mitigate extremely large percentage increases in number of cases starting from very low levels, we added 50 to the number of cases before taking the $\log$, so we actually work with $\Delta \log \left(C_{c t}+50\right)$. The value of 50 was obtained after a grid search to determine which value gave the best fit to the data.

\section{RESULTS}

Here we present empirical results from estimating the consumer panic model of equation (3.6) on the panel data set described in Section 2. First we present results from a simplified model that includes only domestic policy and COVID-19 case data. Then we present results from our full model that also includes international variables. Finally we present results from variants of the model that (i) use a broader panic measure or (ii) allow for "leader" countries (in a sense defined later).

\subsection{Domestic Model}

The first two columns of Table 2, labelled "Model 1," report results from a restricted model that includes only domestic COVID-19 cases and domestic policy variables, omitting the foreign variables from equation (3.6). In this model both the current and lagged change in internal restrictions are highly significant. The point estimates imply that if a government increases internal restrictions by 1 on a $0-5$ scale (e.g. closing schools or restricting gatherings) this causes the panic index to increase by approximately $8.3 \%$ on the same day. (Subsequent changes are more difficult to interpret as the model contains the lagged policy change and two lags of the panic index, so we present impulse response functions later.) The current period stimulus is also significant, but with a smaller effect size, while travel restrictions are insignificant.

Both the percentage and absolute changes in COVID-19 cases are significant determinants of panic, but their interaction is not significant. The point estimates imply that a $10 \%$ increase in confirmed COVID-19 cases increases the panic index by $8.5 \%$, which is similar to the effect of the one unit increase in our internal restriction measure. 
Table 2. Regression Models of Panic during the COVID-19 Pandemic

Models of $\ln \left(\right.$ panic $\left._{c t}\right)$ :

\author{
Model 1 \\ $\beta \quad$ S.E.
}

Model 2

$\beta \quad$ S.E.

Internal Restrictions:

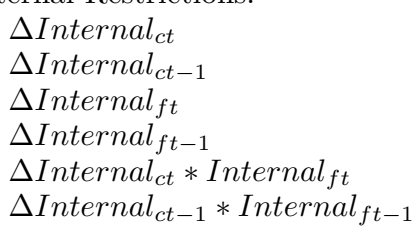

Stimulus Announcements:

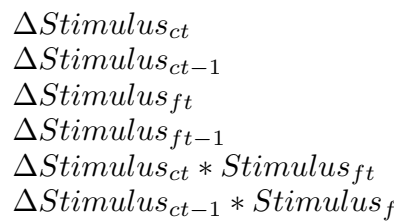

Travel Restrictions:

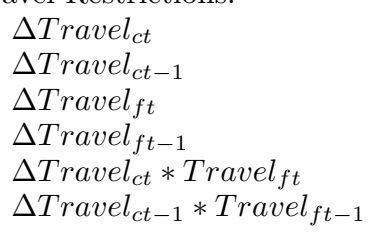

Domestic COVID-19 Cases:

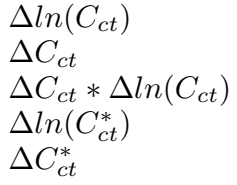

$\begin{array}{rrrr}0.083 & 0.016 & 0.123 & 0.027 \\ 0.069 & 0.016 & 0.144 & 0.031 \\ & & 0.292 & 0.087 \\ & & 0.234 & 0.110 \\ & & -0.032 & 0.013 \\ & & -0.046 & 0.014 \\ & & & \\ 0.052 & 0.022 & 0.102 & 0.044 \\ 0.020 & 0.024 & 0.041 & 0.047 \\ & & 0.068 & 0.138 \\ & & 0.134 & 0.132 \\ & & -0.082 & 0.035 \\ & & -0.038 & 0.037 \\ & & & \\ 0.010 & 0.008 & 0.024 & 0.017 \\ 0.008 & 0.008 & 0.015 & 0.019 \\ & & -0.068 & 0.049 \\ & & -0.064 & 0.042 \\ & & -0.007 & 0.004 \\ & & -0.004 & 0.005 \\ & & & \\ 0.848 & 0.062 & 0.356 & 0.071 \\ 0.004 & 0.002 & 0.004 & 0.002 \\ 0.022 & 0.023 & 0.032 & 0.017 \\ -0.462 & 0.087 & -0.142 & 0.086 \\ -0.004 & 0.005 & -0.006 & 0.004\end{array}$

International COVID-19 Cases:

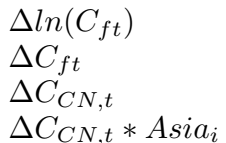

$\begin{array}{rr}0.689 & 0.136 \\ 0.013 & 0.007 \\ -0.001 & 0.003 \\ 0.018 & 0.009\end{array}$

Autoregressive Terms:

$\begin{array}{lllll}\ln \left(\text { panic }_{c t-1}\right) & 0.447 & 0.012 & 0.392 & 0.012 \\ \ln \left(\text { panic }_{c t-2}\right) & 0.251 & 0.012 & 0.235 & 0.012\end{array}$

Diagnostics:
AR1 Term of $\hat{e}_{c t}$
CD Test p-value
$-0.014 \quad 0.013$
0.000
0.000
0.625
0.013
0.152
0.128 $R^{2}-$ Within units
0.636 
The results from this simplified model are suspect however, as the specification tests point to a number of severe problems. On the plus side, we do not find evidence of serial correlation in the residuals, suggesting our lag structure is adequate. Additional lags of the dependent and independent variables were not significant in this model or in the specifications discussed below. However, the Pesaran (2015) test overwhelmingly rejects the null hypothesis of "weak" cross sectional dependence. The implication is that the residuals contain important shocks that are correlated across countries. And a Sims (1972) non-causality test finds that leads of the policy variables are highly significant in the panic equation, thus rejecting the hypothesis that the policy variables are predetermined with respect to consumer panic.

\subsection{Main Specification}

We report results from the full model of (3.6) in the right two columns of Table 2, labelled "Model 2." This model adds international COVID-19 cases and policy variables. Our full model easily passes the Pesaran CD Test and Sim's non-causality test, implying that the international caseload and policy variables account for the non-weak cross-sectional dependence found in Model 1, as well as the error component that predicts future policy.

These results are intuitive in the pandemic context for two reasons: First, it seems clear that foreign caseload and policy changes influence domestic consumer panic. Indeed, quite a few countries experience spikes in the panic index prior to having substantial numbers of confirmed domestic cases. Hence, controlling for the international variables purges the residuals of the component that induces cross-sectional dependence. Both foreign caseload and policy changes clearly have strong influences on future domestic policy decisions. Hence, controlling for the international variables purges the residuals of the component that predicts future domestic policy.

If we estimate the full model of equation (3.6) by applying a within transformation and running OLS (thus obtaining the fixed effects estimator via the Frisch-Waugh theorem) there is evidence of conditional heteroskedasticity. We model this heteroskedasticity as shown in Table 6 of Appendix B and then apply weighted least squares. The variance equation is of interest in itself: It shows the variability of consumer panic is greater when lagged panic is higher, when domestic COVID-19 cases grow more in percentage terms, when international cases grow less in percentage terms, if domestic travel restrictions are tightened (with a one day lag), and if foreign travel restrictions are relaxed.

In the full model both the current and lagged change in internal restrictions are again highly significant. As we see in Table 2, the average level of internal restrictions in foreign countries is also a significant positive determinant of domestic consumer panic, suggesting that domestic consumers use foreign government policy as a signal of the severity of the pandemic and/or to predict their own government's future policy. The magnitude of the coefficients on the foreign averages is roughly double those on domestic restrictions, but note that changes in the international averages tend to be smaller from day to day.

Furthermore, the interactions between domestic internal restrictions and the average level of restrictions in foreign countries are negative and significant. This supports our key hypothesis that internal restrictions tend to cause less domestic consumer panic if they are introduced relatively late in the pandemic compared to other countries.

Figure 6 shows impulse response functions for domestic internal movement restrictions, evaluated at the average international level of internal restrictions on three different dates: Feb 21 (early), March 13 (middle) and April 1 (late). If a government increases 
internal restrictions by one unit (e.g. closing schools or restricting gatherings) on Feb 21 it causes the panic index to increase by approximately $12 \%$ on the same day. The effect peaks at about $18 \%$ on day 2 , and then gradually vanishes after about a week to ten days. But if a government delays until March 13 the peak is only about $13 \%$ on day 2, and if the government delays until April 1st the impulse response function shows no significant effects (although the short-run impact is imprecisely estimated and the confidence interval covers a range of about $+10 \%$ to $-10 \%$ on the first and second day).

Figure 6. Impulse Response Functions For Policy Change

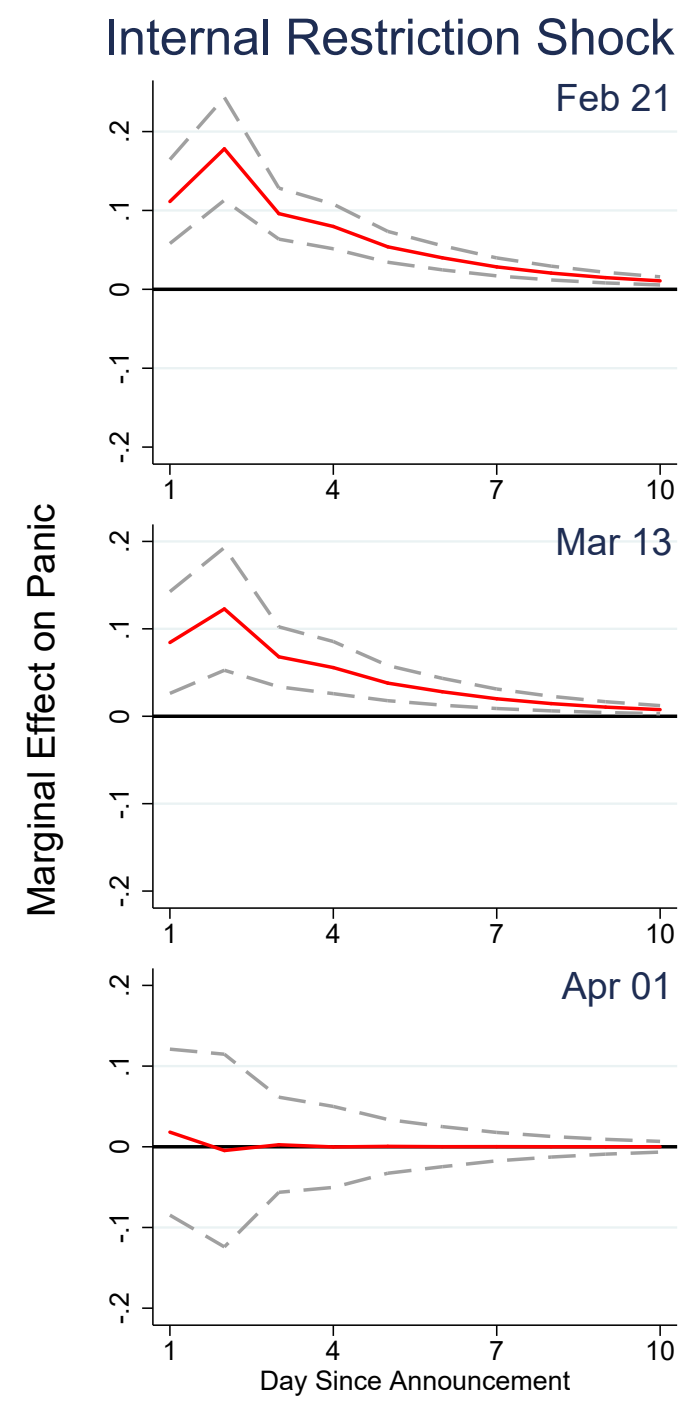

Stimulus Announcement
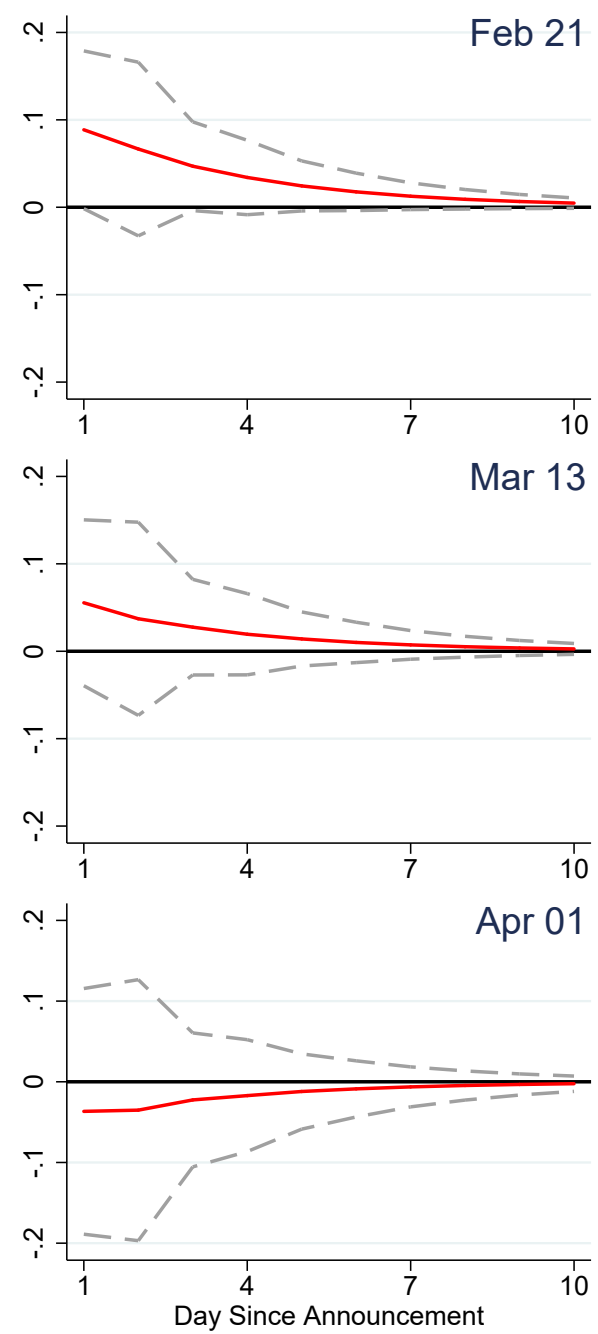
Our point estimates imply that stimulus announcements also have a positive short-run effect on consumer panic. Again, the interaction with the international average of stimulus announcements is also significant, implying the effect is lessened if the announcement comes "late" relative to other countries. But the impulse response functions on the right side of Figure 6 show the effects of stimulus announcements are both weaker and less precisely estimated than those of internal movement restrictions. As was the case with internal restrictions, we find the effect of stimulus announcements on panic diminishes if they come later in the pandemic. We find no statistically or quantitatively significant effects of travel restrictions (impulse response not shown).

Finally, we consider the role of COVID-19 caseloads. Both percentage and absolute changes in domestic COVID-19 cases are significant and positive drivers of panic, as is the interaction between the two. Given our flexible specification, the overall effect of a given increase in cases depends on both the percentage and absolute change. The impulse response functions in the left panel of Figure 7 show the effects of average increases of COVID-19 cases in February, March and April. The average (across all countries) of the daily increases were $1 \%$ on a base of 15 cases in February, $11 \%$ on 2,900 cases in March, and $7.3 \%$ on 18,600 cases in April. Thus, both percentage and absolute changes tend to be small in February. The largest percentage increases tend to be in March, and the largest absolute increases tend to be in April.

Our model implies the typical March daily increase in caseloads would have increased the panic index by about $4 \%$ immediately, with an effect that dies off over time, becoming negligible after about a week. Effects of typical April changes in caseloads are about $25 \%$ smaller. This combined with the fact that most policy announcements were concentrated in March (see Figure 3) is consistent with the fact that most countries saw very low levels of the panic index in February, following by peaks of the panic index during March, with the index declining through April (see Figures 1, 4, 5).

Interestingly, we find that surprise changes in domestic cases have no greater effect on panic that absolute changes. Thus, it seems that consumers react to the total changes in cases, rather than reacting to the surprise component per se.

International COVID-19 cases are very significant determinants of domestic panic, both statistically and quantitatively. Impulse response functions in the right panel of Figure 7 show effects of average increases in worldwide COVID-19 cases in February, March and April. ${ }^{15}$ Our model implies the typical March daily increase in caseloads increased the panic index by about $11 \%$ immediately, with an effect that dies off over time, becoming negligible after about a week. Effects of typical April changes in caseloads are similar. Comparing these impulse response functions to those for domestic cases in the left panel of Figure 7, we see that international cases have substantially larger effects on domestic panic that domestic cases. This makes sense, give that large caseloads were concentrated in a relatively few countries, while panic was widespread across many countries.

Finally, we find that cases in China are a significant determinant of panic in East and Southeast Asian countries, but not elsewhere. Overall, we have found that both international policy regimes and international cases are important drivers of domestic panic, suggesting that consumers do pay attention to international conditions.

${ }^{15}$ As we noted earlier, the average (across all countries) of the daily increases are $1 \%$ on a base of 15 cases in February, $11 \%$ on 2,900 cases in March, and $7.3 \%$ on 18,600 cases in April. The international average caseload changes used to construct the right panel of Figure 7 are the same as the average domestic changes use to construct the left panel. 
Figure 7. Impulse Response Functions For COVID-19 Case Increases
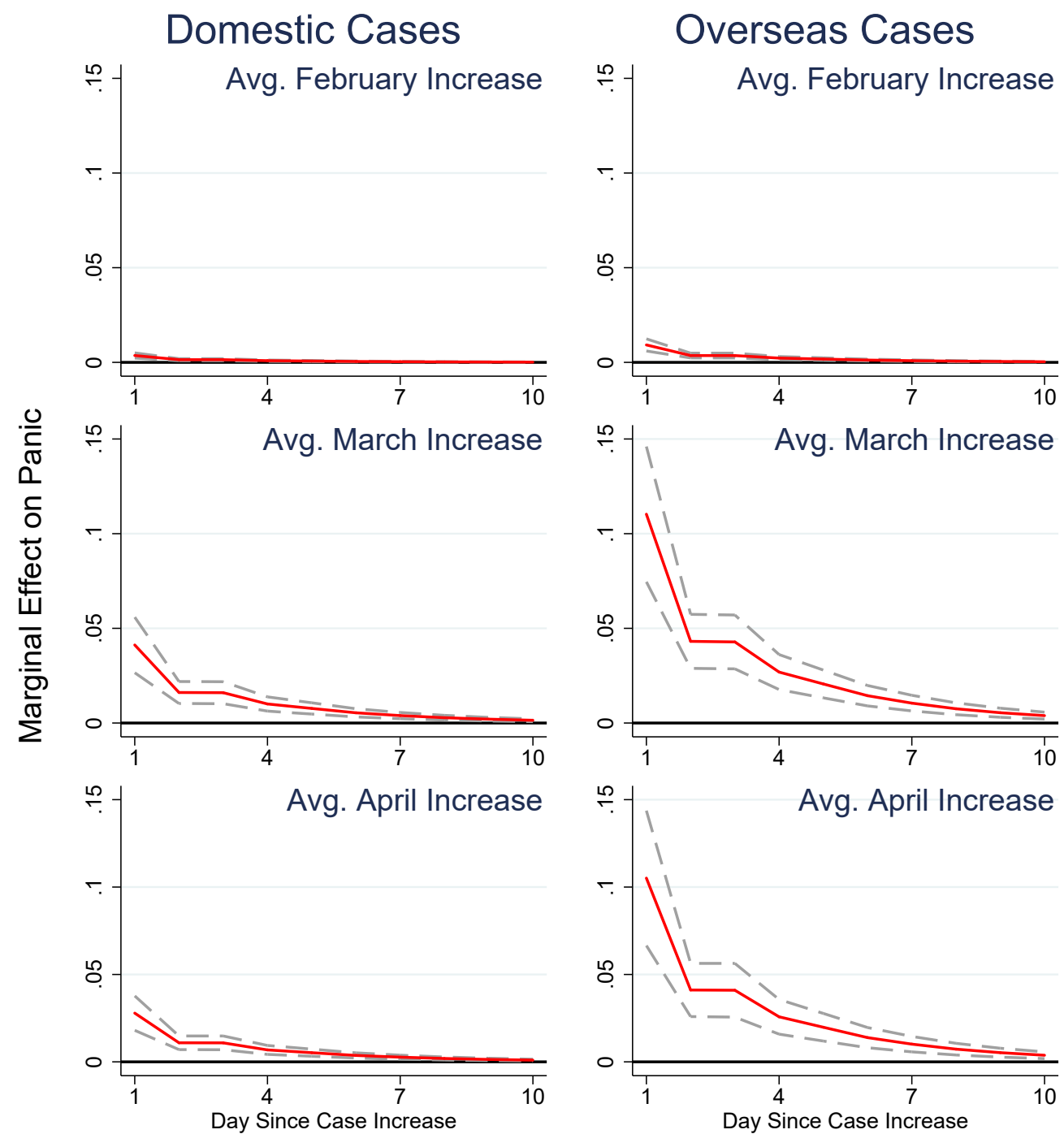

Note: The average daily increase in February is a percentage increase of $1 \%$ and absolute increase of 2, in March it is a percentage increase of $11 \%$ and absolute increase of 314, and in April it is a percentage increase of $5.5 \%$ and absolute increase of 1,564 .

\subsection{Model Fit}

Figure 8 illustrates how the model fits the time series of the panic index data for selected countries. The figure presents fitted values of the daily panic index based on current and lagged values of the forcing variables (i.e., policy variables and COVID-19 cases). We present both conditional predictions, where the two lags of the panic index in equation (3.6) are always set at their true values, and unconditional predictions, where we plug

(C) 2020 
in the two previous day's predicted panic indices from the model. Italy and France are examples of countries where the model provides very good predictions of the path of the panic index based on the forcing variables.

Our model fits the UK somewhat less well, as the conditional predictions only generate about half to two-thirds of the increase in panic. This is largely due to the fact that UK panic index rises to substantially higher levels than those of Italy and France, and the large UK increase is not easy to explain based on the forcing variables. Also, referring back to Figure 5, one can see that in Italy and France domestic cases began to rise and internal restrictions were announced prior to the large spike in panic in early to midMarch. But in the UK panic increased substantially prior to the emergence of substantial domestic cases or internal restrictions. So the increase in panic in the UK in early March is driven largely by international cases and policies.

Australia is an example of a country where the panic index had a massive spike on a particular day (March 2) and the model is not able to explain why this occurred. As we noted in Section 2, the increase in the panic index in Australia was an order of magnitude greater than we observe in almost any other country, so it is not at all surprising that our model cannot explain it. The other countries with similar hard to explain massive spikes are Japan, Taiwan and Singapore. ${ }^{16}$ It is of course not surprising that a variable like "panic" is sometimes hard to predict based only on observed forcing variables, so we would argue that - with the exception of this set of countries - the model generally fits quite well. (An Appendix showing the fit for all 54 countries is available on request).

\subsection{Discussion}

As we discussed in Section 3.1, there are four channels through which internal restrictions may plausibly affect consumer panic, and the overall effect depends on the balance of these four. Recall that internal restrictions: (i) increase the cost of store visits, which increases desired inventories, leading to a short-run spike in demand, (ii) increase expected future costs of store visits, with a similar effect, (iii) increase perceived severity of the pandemic, which may increase consumer panic, and (iv) reduce expected future severity of the pandemic, which may reduce consumer panic. Estimates from a reduced form model cannot disentangle these different channels, but our model implies that the three panic increasing effects dominate until very late March and early April.

Our model also implies that stimulus announcements have a significant positive effect on consumer panic in the short-run, but the point estimates imply this is much weaker than the effect of internal restrictions. A weaker effect seems plausible, as stimulus announcements do not have any plausible effects on the cost of store visits, so channels (i)-(ii) are not operative. Their only positive effect on consumer panic would seem to operate through channel (iii), as they may signal greater severity of the pandemic.

Our model implies that travel restrictions have no significant effect on consumer panic. Again, travel restrictions have no plausible effects on costs of store visits, so channels (i)-(ii) are not operative. Our results suggest that the signalling effect of travel restrictions, operating through channel (iii), is fully counter-balanced by channel (iv), whereby

${ }^{16}$ In addition, the model under-predicts the magnitude of early panic spikes in the US, Canada, Mexico and Germany. But, unlike Australia, Japan, Taiwan and Singapore, it underestimates the magnitude of the spikes rather than missing them altogether (similar to the case of the UK). 
Figure 8. Conditional and Unconditional Predictions of Log Panic from Model 2

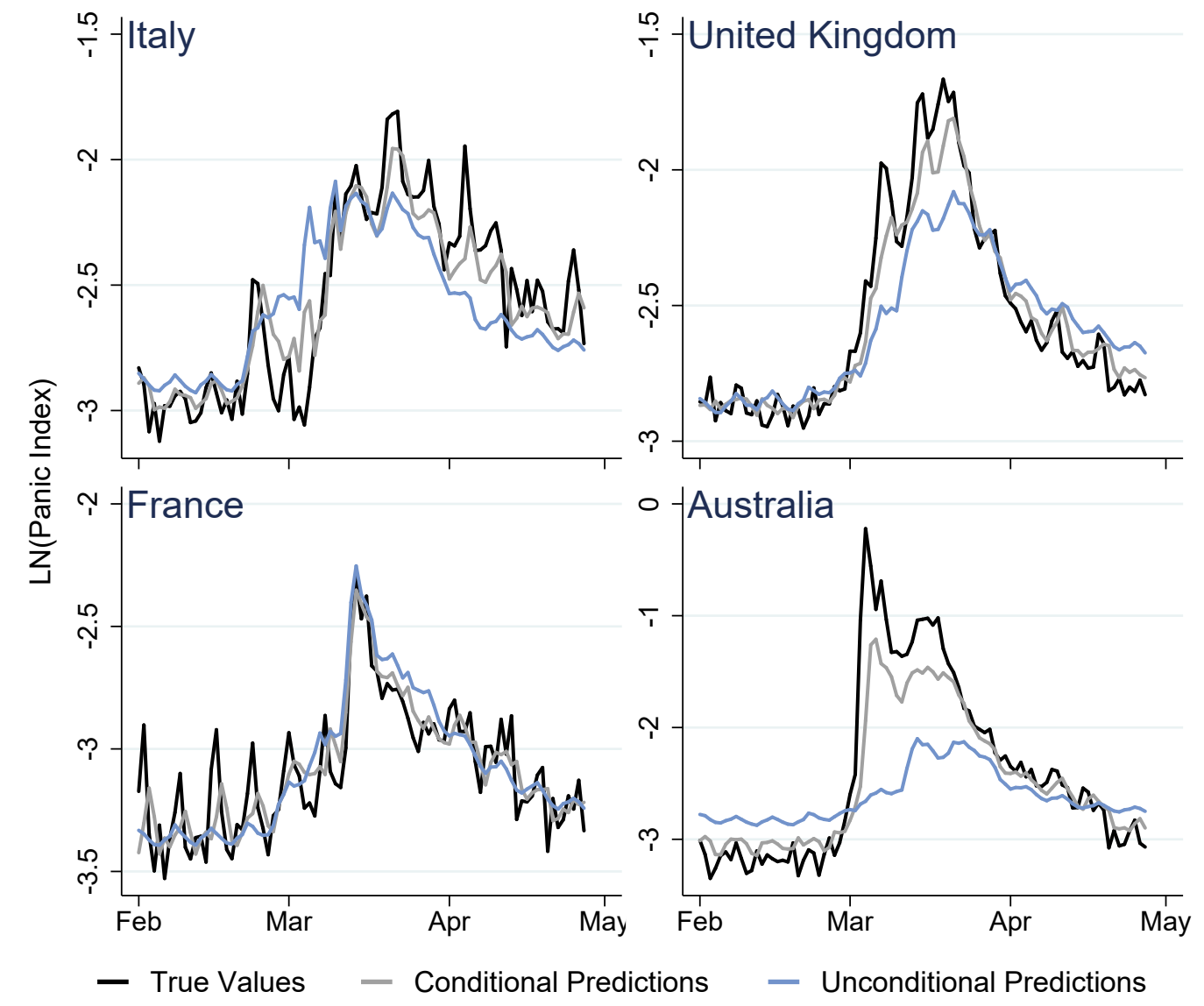

consumers expect that travel restrictions will help mitigate the severity of the pandemic in the future, thus reducing panic.

Another key finding is that both foreign cases and the policy decisions of foreign governments contribute to domestic panic. A model that fails to account for this was found to be seriously misspecified, as it suffered from meaningful cross-sectional dependence and a failure of the predetermination assumption for the domestic policy variables. This is because the foreign caseload and policy variables contribute not only to domestic consumer panic in the short run, but also to future domestic policy decisions.

\subsection{Alternative Specifications}

Here we consider two alternative specifications of the baseline model. First, we consider a broader definition of the panic index that incorporates fear of future economic insecurity by adding the search terms "recession" and "unemployment" to the index. In most countries the extended panic index behaves similarly to our original index, but the notable exceptions are the United States, France, Mexico, and South Africa. Figure 9 compares the standard panic index to the extended index for the United States. Due to frequent 
searches for 'unemployment' in late-March and April, the extended panic index does not decline after the surge in early to mid-March. This suggests that in some countries economic fears and insecurity do not disappear as quickly as does fear of shortages. ${ }^{17}$

Figure 9. Panic Indexes and Model Predictions for the United States

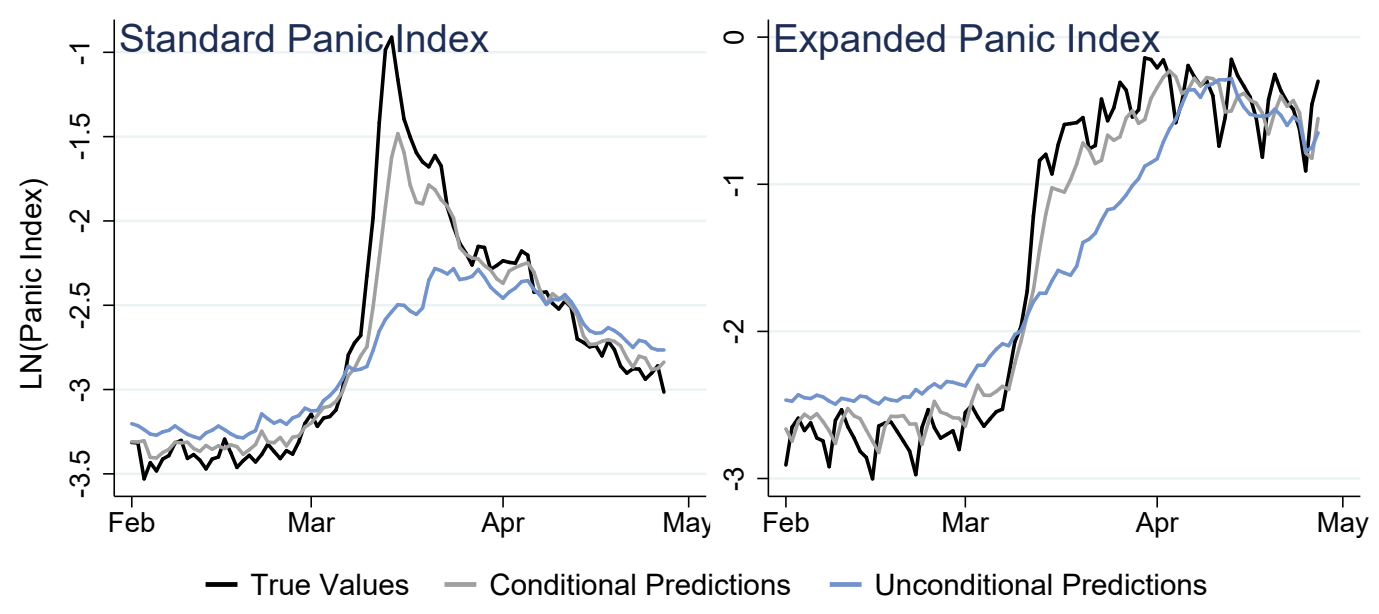

The left two columns of Table 3, labelled 'Model 3,' present our results for the extended panic index. They are very similar to those for Model 2. The interaction between the change in internal restrictions and the average level of restrictions is now smaller in magnitude and only significant at the $10 \%$ level. But the one day lag of this interaction is larger and more significant. Hence, our key hypothesis that internal restrictions tend to cause less domestic consumer panic if they are introduced relatively late in the pandemic compared to other countries is still supported. The coefficients on average internal restrictions are smaller, particularly the lag which is no longer significant, but the coefficient on the present term remains sizable and significant. The autoregressive term for the first lag slightly increases, reflecting more persistence in the version of the index that incorporates economic fears (which may subside slower than a fear of shortages).

While the AR1 term of $\hat{e}_{c t}$ is very small for Model 3, the CD Test rejects the null hypothesis of weak cross-sectional dependence, with a p-value of 0 and a test statistic of 4.43 (distributed $\mathrm{N}(0,1)$ ). This is in contrast to Model 2, where the null was not rejected. It is perhaps not surprising that longer term conditions like unemployment are more correlated across linked economies than are consumer goods shortages.

It is important to note that rejecting the null of weak cross-sectional dependence does not necessarily imply inconsistency in the estimates. Furthermore, as Pesaran (2015) notes the test will over-reject when $T$ is large relative to $N$. Looking at the matrix of cross-sectional correlations of residuals between pairs of countries, only $0.7 \%$ of the pairs have a correlation above 0.25 , with the maximum correlation being 0.36 . Over $86 \%$ of the pairs have a correlation below 0.1 , which leads us to doubt that cross-section dependence is causing significant bias in this case. Given that the test over-rejects with the dimensions of our panel data, it is actually quite impressive that Model 2 passes the CD test with a p-value above 0.1 .

17 Figure 9 also shows predicted values of the panic index from our models. It it worth recalling that the US is one of the countries where our panic index spikes most sharply and our model fit is worst. 
Table 3. Regression Models of Panic during the COVID-19 Pandemic

\begin{tabular}{|c|c|c|c|c|}
\hline \multirow{2}{*}{ Models of $\ln \left(\right.$ panic $\left._{c t}\right)$ : } & \multicolumn{2}{|c|}{ Model 3} & \multicolumn{2}{|c|}{ Model 4} \\
\hline & $\beta$ & S.E. & $\beta$ & S.E. \\
\hline \multicolumn{5}{|l|}{ Internal Restrictions: } \\
\hline$\Delta$ Internal $_{c t}$ & 0.092 & 0.030 & 0.110 & 0.033 \\
\hline$\Delta$ Internal $c t-1$ & 0.152 & 0.036 & 0.143 & 0.036 \\
\hline$\Delta$ Internal $_{f t}$ & 0.279 & 0.087 & 0.252 & 0.090 \\
\hline$\Delta$ Internal $_{f t-1}$ & 0.136 & 0.108 & 0.208 & 0.111 \\
\hline$\Delta$ Internal $_{c t} *$ Internal $_{f t}$ & -0.018 & 0.013 & -0.023 & 0.014 \\
\hline$\Delta$ Internal $_{c t-1} *$ Internal $_{f t-1}$ & -0.053 & 0.014 & -0.047 & 0.015 \\
\hline \multicolumn{5}{|l|}{ Stimulus Announcements: } \\
\hline$\Delta$ Stimulus $_{c t}$ & 0.078 & 0.048 & 0.125 & 0.051 \\
\hline$\Delta$ Stimulus $_{c t-1}$ & -0.013 & 0.044 & 0.056 & 0.046 \\
\hline$\Delta$ Stimulus $_{f t}$ & 0.073 & 0.138 & 0.069 & 0.139 \\
\hline$\Delta$ Stimulus $_{f t-1}$ & 0.048 & 0.131 & 0.139 & 0.134 \\
\hline$\Delta$ Stimulus $_{c t} *$ Stimulus $_{f t}$ & -0.025 & 0.039 & -0.096 & 0.040 \\
\hline$\Delta$ Stimulus $_{c t-1} *$ Stimulus $_{f t-1}$ & 0.024 & 0.036 & -0.053 & 0.038 \\
\hline \multicolumn{5}{|l|}{ Travel Restrictions: } \\
\hline$\Delta$ Travel $_{c t}$ & 0.015 & 0.017 & 0.025 & 0.017 \\
\hline$\Delta$ Travel $_{c t-1}$ & 0.009 & 0.017 & 0.012 & 0.018 \\
\hline$\Delta$ Travel $_{f t}$ & -0.038 & 0.048 & -0.051 & 0.049 \\
\hline$\Delta$ Travel $_{f t-1}$ & -0.042 & 0.038 & -0.060 & 0.040 \\
\hline$\Delta$ Travel $_{c t} *$ Travel $_{f t}$ & -0.005 & 0.004 & -0.007 & 0.004 \\
\hline$\Delta$ Travel $_{c t-1} *$ Travel $_{f t-1}$ & -0.003 & 0.004 & -0.002 & 0.004 \\
\hline \multicolumn{5}{|l|}{ Domestic COVID-19 Cases: } \\
\hline$\Delta \ln \left(C_{c t}\right)$ & 0.347 & 0.072 & 0.353 & 0.074 \\
\hline$\Delta C_{c t}$ & 0.017 & 0.002 & 0.002 & 0.002 \\
\hline$\Delta C_{c t} * \Delta \ln \left(C_{c t}\right)$ & 0.025 & 0.020 & 0.045 & 0.019 \\
\hline$\Delta \ln \left(C_{c t}^{*}\right)$ & -0.114 & 0.087 & -0.135 & 0.089 \\
\hline$\Delta C_{c t}^{*}$ & -0.018 & 0.006 & -0.005 & 0.004 \\
\hline \multicolumn{5}{|l|}{ International COVID-19 Cases: } \\
\hline$\Delta \ln \left(C_{f t}\right)$ & 0.715 & 0.134 & 0.619 & 0.137 \\
\hline$\Delta C_{f t}$ & 0.031 & 0.007 & 0.015 & 0.007 \\
\hline$\Delta C_{C h i n a, t}$ & -0.000 & 0.003 & -0.000 & 0.003 \\
\hline$\Delta C_{C h i n a, t} *$ Asia $_{i}$ & 0.019 & 0.009 & 0.020 & 0.009 \\
\hline \multicolumn{5}{|l|}{ Leader Panic: } \\
\hline Contemporaneous Term & & & 0.338 & 0.042 \\
\hline First Lag & & & -0.145 & 0.056 \\
\hline Second Lag & & & -0.127 & 0.040 \\
\hline \multicolumn{5}{|l|}{ Autoregressive Terms: } \\
\hline $\ln \left(\right.$ panic $\left._{c t-1}\right)$ & 0.435 & 0.012 & 0.403 & 0.012 \\
\hline $\ln \left(\right.$ panic $\left._{c t-2}\right)$ & 0.241 & 0.012 & 0.235 & 0.012 \\
\hline \multicolumn{5}{|l|}{ Diagnostics: } \\
\hline AR1 Term of $\hat{e}_{c t}$ & -0.008 & 0.013 & 0.021 & 0.013 \\
\hline CD Test p-value & \multicolumn{2}{|c|}{0.000} & \multicolumn{2}{|c|}{0.812} \\
\hline Sims Test p-value & \multicolumn{2}{|c|}{0.055} & \multicolumn{2}{|c|}{0.256} \\
\hline$R^{2}-$ Within units & \multicolumn{2}{|c|}{0.722} & \multicolumn{2}{|c|}{0.640} \\
\hline
\end{tabular}

Note: Model 3 uses a definition of Panic that includes both recession and unemployment, and is estimated by WLS. Model 4 adds the Leader Panic variable that addresses the occasionally significant cross-sectional correlations that are observed (C) 2020 Appendix.

in the residuals to Model 2. The results for additional terms are available in the 
Examining the cross-sectional correlation matrix of Model 2's residuals, most of the pairs with non-trivial correlations make intuitive sense. For instance, the errors for Canada and the United States are positively correlated, suggesting that panic in Canada is strongly related to panic in its much larger neighbor. If the two countries peak in panic around the same time and the model under-estimates that peak, then the errors are going to be correlated. Other examples of the errors of small countries being highly correlated with their large neighbors include Belgium and the Netherlands with France, Uruguay with Brazil, and the UAE with Saudi Arabia. This suggests that it is possible to expunge Model 2 of its weak cross-section dependence by allowing the panic of these small countries to react to the present value and the lags of the larger neighbor's panic. We do this by creating a 'Leader Panic' variable, which for the small neighbor takes the value of the larger neighbor's panic. ${ }^{18}$

The results can be seen in the right two columns of Table 3 listed under Model 4. The coefficients for the 'Leader Panic' variable are all significant. The contemporaneous coefficient is strongly positive, which indicates that consumer panic in these smaller countries is highly correlated with panic in their larger neighbors, or leader, even after controlling for its own lag and all of the policy and COVID-19 case variables. After including the 'leader' variable the p-value of the $\mathrm{CD}$ test increases from 0.15 to 0.81 indicating even less cross-section dependence in the error term than in Model 2. The remainder of the coefficients are similar enough to support all of the conclusions from our interpretation of the results of Model 2, confirming that the weak cross-section dependence found in Model 2 does not cast any doubt on the validity of the conclusions.

\section{CONCLUSION}

Panic buying of storable consumer goods is a common phenomenon during natural disasters and man-made crises. But consumer panic has been little studied from an econometric point of view (A notable exception being Hansman et al. 2020). This is because of the difficulty of obtaining suitable data, and the lack of variation in the determinants of panic. Typical panics are one-off events where consumers in a particular location react to news of a crisis (e.g., an approaching hurricane) by stockpiling consumer goods. The nature of such a panic makes it difficult to study using conventional econometric methods: First, relevant high frequency data on consumer response is difficult to obtain because of the very suddenness of the event. Second, panic events (like a hurricane) typically affect a particular group pf consumers in a particular location at about the same time. Thus it is hard to find variation in the forcing variables that drive the a panic.

The COVID-19 pandemic provides a unique opportunity to study consumer panic for two reasons: First, the panic has affected nearly every country on earth, but at different times and to different degrees. Thus, there is a great deal of variation across locations in the timing and severity of the panic-inducing event. Furthermore, governments have responded to the pandemic with a variety of different policies implemented at different times and with differing strictness, generating variation in the policy drivers of panic.

The first contribution of this article is to construct a daily index of consumer panic

${ }^{18}$ The complete list of assignments are as follows: The US leads Mexico and Canada, France leads Belgium and the Netherlands, Brazil leads Uruguay and Argentina, Saudi Arabia leads the UAE, Italy leads Spain, and Australia leads the UK. Regarding the final two assignments, the country's roles could be switched to the same effect. The UK and Australia may have a strong correlation in panic simply due to historical and cultural bonds. 
for 54 countries, covering the key period from January 1st to late April 2020. Spikes in the index align well with the timing of stockpiling as measured in the IRI (2020) data for the subset of countries where IRI data is available. We also construct daily data on government policy announcements in response to the pandemic, including internal movement restrictions, travel restrictions and economic stimulus. And we collect daily data on COVID-19 cases for all 54 countries.

The result is a high-frequency panel dataset on consumer panic, government policy and COVID-19 cases that covers many countries over a key four month period of the pandemic. By exploiting the heterogeneity in the timing and severity of panic, along with the heterogeneity in governmental policy response and virus transmission, a panel data model is better placed to overcome issues of spurious regression that would inevitably arise from a time series or cross-sectional study of the same problem.

The second contribution of this article is to build a dynamic model that allows for panic to respond to domestic and international policy change, and domestic and international virus transmission. Importantly, our model allows the effect of domestic policy to depend on the international context. We show that a model that attempts to predict panic based only on domestic events is seriously misspecified, but that a model that incorporates the international context passes a stringent set of specification tests.

Our results show that the announcement of internal movement restrictions generates considerable consumer panic in the short-run, but the effect largely vanishes after a week to ten days. Consumer panic also responds to announcements of internal movement restrictions in foreign countries, suggesting that consumers take these as a signal of the severity of the pandemic and/or likely future policy in their home country. Furthermore, internal movement restrictions generate less panic if they are implemented relatively late compared to other countries. The other two policies we consider, travel restrictions and stimulus announcements, do not appear to generate significant consumer panic.

Consumer panic is also sensitive to both domestic and worldwide COVID-19 cases. We find that consumers are most sensitive to changes in COVID-19 cases that are large in both percentage and absolute terms. They are less responsive to large percentage increases from a small base, or large absolute changes from a large base. This emphasises the midway point of the curve of new COVID-19 cases.

It is important for governments to better understand how to minimize consumer panic while pursuing their policy goals in a pandemic environment. For example, one possible lesson for government is that, in the early stages of a pandemic, when internal restrictions are first being contemplated, large retailers could be advised to carry extra stock of key consumer goods. Given that the panic induced by internal restrictions is sudden but short lived, having extra stock to handle and an initial surge in demand could prevent shortages and hence prevent consumer panic from taking hold in the first place.

It is particularly important to learn lessons from the COVID-19 pandemic given that future pandemics are essentially inevitable, whether in the near term from a second wave or new strain of COVID-19, or longer term as new virus strains emerge. This article is the first attempt to model the determinants of consumer panic in a pandemic environment, but there is significant scope for this to be an area of active future research. 
Acknowledgements: This research was supported by Australian Research Council grants FL110100247 and CE170100005. The authors acknowledge Yuanyuan Deng, Inka Eberhardt, Katja Hanewald, Heloise Hardy, Shahin Kiaei, George Kurdna, Seojeong Lee, Shiko Maruyama, Peyman Firouzi Naeim, Miguel Olivo-Villabrille, Thanh Phan, Olena Stavrunova, and Nada Wasi for assistance with translations.

\section{References}

Avery, C., W. Bossert, A. Clark, G. Ellison, and S. F. Ellison (2020). Policy implications of models of the spread of Coronavirus: Perspectives and opportunities for economists. NBER Working Paper No. 27007.

Chinazzi, M., J. T. Davis, M. Ajelli, C. Gioannini, M. Litvinova, S. Merler, A. P. y Piontti, K. Mu, L. Rossi, K. Sun, et al. (2020). The effect of travel restrictions on the spread of the 2019 novel coronavirus (COVID-19) outbreak. Science 368(6489), 395-400.

Choi, H. and H. Varian (2012). Predicting the present with Google trends. Economic record $88,2-9$.

Da, Z., J. Engelberg, and P. Gao (2011). In search of attention. The Journal of Finance 66(5), 1461-1499.

Erdem, T., S. Imai, and M. P. Keane (2003). Brand and quantity choice dynamics under price uncertainty. Quantitative Marketing and economics 1(1), 5-64.

Fang, H., L. Wang, and Y. Yang (2020). Human mobility restrictions and the spread of the novel coronavirus (2019-ncov) in China. NBER Working Paper No. 26906.

Ferguson, N., D. Laydon, G. Nedjati Gilani, N. Imai, K. Ainslie, M. Baguelin, S. Bhatia, A. Boonyasiri, Z. Cucunuba Perez, G. Cuomo-Dannenburg, et al. (2020). Report 9: Impact of non-pharmaceutical interventions (NPIs) to reduce COVID19 mortality and healthcare demand. Imperial College London.

Ginsberg, J., M. H. Mohebbi, R. S. Patel, L. Brammer, M. S. Smolinski, and L. Brilliant (2009). Detecting influenza epidemics using search engine query data. Nature 457(7232), 1012-1014.

Goel, S., J. M. Hofman, S. Lahaie, D. M. Pennock, and D. J. Watts (2010). Predicting consumer behavior with web search. Proceedings of the National academy of sciences 107(41), 17486-17490.

Grohol, J. (2020). Panic buying: The psychology of hoarding toilet paper, beans and soup. PsychCentral. Available online: https://psychcentral.com/blog/ panic-buying-the-psychology-of-hoarding-toilet-paper-beans-soup/.

Hansman, C., H. Hong, A. de Paula, and V. Singh (2020). A sticky-price view of hoarding. NBER Working Paper No. 27051.

Hori, M. and K. Iwamoto (2014). The run on daily foods and goods after the 2011 Tohoku earthquake: a fact finding analysis based on homescan data. The Japanese Political Economy 40(1), 69-113.

Hughes, W. T. (1988). A tribute to toilet paper. Reviews of infectious diseases 10(1), 218-222.

IRI (2020). Covid-19 impact: Consumer spending tracker for measured channels. Information Resources Inc. Available online at: https://www.iriworldwide.com/IRI/ media/Library/2020-04-30-IRI-BCG-COVID-Global-Consumer-Spend-Tracker . pdf.

Ishida, T., A. Maruyama, and S. Kurihara (2013). Consumer reaction to the Great East Japan Earthquake. Journal of Life Sciences 7(8), 883. 
Knoll, C. (2020). Panicked shoppers empty shelves as coronavirus anxiety rises. The New York Times. Available online: https://www.nytimes.com/2020/03/13/nyregion/ coronavirus-panic-buying.html.

Kurihara, S., A. Maruyama, and A. Luloff (2012). Analysis of consumer behavior in the Tokyo metropolitan area after the Great East Japan Earthquake. Journal of Food System Research 18(4), 415-426.

Lampos, V., S. Moura, E. Yom-Tov, I. J. Cox, R. McKendry, and M. Edelstein (2020). Tracking COVID-19 using online search. arXiv preprint arXiv:2003.08086.

Malcolm, A. (1974). The 'shortage' of bathroom tissue: Classic study in rumor. The New York Times. Available online: https://www.nytimes.com/1974/02/03/archives/ the-shortage-of-bathroom-tissue-a-classic-study-in-rumor-shortage. html.

Musvanhiri, P. (2017). Zimbabweans stock up on essentials amid fears of hyperinflation. Deutsche Welles. Available online: https://www.dw.com/en/ zimbabweans-stock-up-on-essentials-amid-fears-of-hyperinflation/ a-40724529.

Nickell, S. (1981). Biases in dynamic models with fixed effects. Econometrica: Journal of the Econometric Society, 1417-1426.

Pesaran, M. H. (2015). Testing weak cross-sectional dependence in large panels. Econometric Reviews 34(6-10), 1089-1117.

Rieder, K. (2020). What we may learn from historical financial crises to understand and mitigate COVID-19 panic buying. VOXeu. https://voxeu.org/article/ mitigating-covid-19-panic-buying-lessons-historical-financial-crises.

Sims, C. A. (1972). Money, income, and causality. The American economic review 62(4), $540-552$. 


\section{APPENDIX A: PREDICTING COVID-19 CASES}

Recall that our model allows surprise changes in COVID-19 cases to have a differential effect on consumer panic. Here we present the model we use to predict daily growth in COVID-19 cases. We interpret the residuals from this model as the component of growth that could be viewed as unexpected or a 'surprise', and that we then enter in (3.6).

We use a very simple $\mathrm{AR}(2)$ model that contains a cubic in number of days since the first confirmed case, along with the measures of the internal restriction and travel restriction policy variables:

$$
\begin{aligned}
f\left(C_{c t}\right)= & \sum_{\ell=1}^{2} \rho_{\ell} f\left(C_{c t-\ell}\right)+\gamma_{0}+\gamma_{1} \text { first }_{c t}+\gamma_{2} f_{i r s t_{c t}^{2}}^{2}+\gamma_{3} f i r s t_{c t}^{3} \\
& +\gamma_{4} \tilde{I}_{c t}+\gamma_{5} \tilde{T}_{c t}+u_{c t}
\end{aligned}
$$

where $f()$ is either $\Delta \log \left(C_{c t}+50\right)$ or $\Delta C_{c t}$ depending on whether we are forecasting the change in log or absolute cases. The variable first $_{c t}$ is the number of days since the first case was detected in the country. In estimation we exclude all observations where the virus is not yet present in a country, i.e., first $t_{c t}=0$, so we use an unbalanced panel.

We assume that internal restrictions and travel restrictions affect the growth of cases with a long lag. To capture this, we define moving averages of past policy. For internal restrictions we define $\tilde{I}_{c t}=0.9 * \tilde{I}_{c t-1}+0.1 *$ Internal $_{c t}$, where Internal $_{c t}$ is the internal restriction policy variable defined in the text, and likewise for $\tilde{T}_{c t}$.

The error term $u_{c t}$ captures unexpected changes in cases. We collect $\hat{u}_{c t}$ from these models and use it as the surprise terms $\Delta \ln C_{c t}^{*}$ and $\Delta C_{c t}^{*}$ in (3.6).

\begin{tabular}{|c|c|c|c|c|}
\hline \multirow{2}{*}{ Dependent Variable: } & \multicolumn{2}{|c|}{$\Delta \ln \left(\right.$ cases $\left._{i, t}+50\right)$} & \multicolumn{2}{|c|}{$\Delta$ cases $_{i, t}$} \\
\hline & $\beta$ & S.E. & $\beta$ & S.E. \\
\hline \multicolumn{5}{|c|}{ Time Since First Case $(\div 1000)$ : } \\
\hline Level & 0.2366 & 0.4284 & 0.0646 & 4.0202 \\
\hline Square & -0.0013 & 0.0101 & 0.0692 & 0.1003 \\
\hline Cube & -0.0000 & 0.0001 & -0.0008 & 0.0007 \\
\hline \multicolumn{5}{|c|}{ Moving Average Policy Variables: } \\
\hline Internal Restrictions & -0.0032 & 0.0010 & -0.0315 & 0.0118 \\
\hline Travel Restrictions & 0.0006 & 0.0006 & 0.0120 & 0.0070 \\
\hline \multicolumn{5}{|l|}{ Autoregressive Terms: } \\
\hline First Lag & 0.4361 & 0.0155 & 0.3870 & 0.0152 \\
\hline Second Lag & 0.3392 & 0.0155 & 0.6305 & 0.0159 \\
\hline Constant Term & 0.0186 & 0.0049 & -0.0013 & 0.0424 \\
\hline$N$ & \multicolumn{2}{|c|}{3722} & \multicolumn{2}{|c|}{3884} \\
\hline$R^{2}$ & \multicolumn{2}{|c|}{0.518} & \multicolumn{2}{|c|}{0.935} \\
\hline
\end{tabular}

Table 4. Regression Models of Confirmed Cases

The results of estimating the two models are presented in Table 4. The first and 
second lags of the dependent variable are highly significant in both models, with the coefficients suggesting moderate levels of state-dependence for the change in log cases and stronger dependence for the absolute change in cases. Interestingly, the time since first case is insignificant in both models. The moving average of internal restrictions is found to negatively affect the growth of the virus in both models to a statistically significant degree. Travel restrictions, in contrast, are not found to be significant.

A more sophisticated empirical model of COVID-19 cases would also include factors such as population density, take-up of restriction measures, climate, and the amount of resources devoted to testing and contact tracing. Nevertheless, the models presented here provide a simple indication of whether the daily growth of cases in any particular country is more or less than what is reasonable to expect, given its own prior history and the experience of other countries in the sample. 


\section{APPENDIX B: MISCELLANEOUS PARAMETERS IN THE REGRESSION MODELS}

Here we present the day of the week effects and constant terms for the models in Tables 2 and 3. Table 5 presents the estimates of these parameters for Models 1 to 4 . All estimates are relative to Sunday which is omitted.

Models 1, 2 and 4 exhibit a strong positive Saturday effect that is nearly as large as the mean of the consumer panic index. This implies consumers are more interested in shopping activity on Saturday. Conversely, the day of the week effects are negative and significant for Monday and Tuesday. It is important to note that these are the average effects across the 54 countries in the sample. Some countries have more pronounced day of the week effects, as can be observed for example in Figure 5 for France.

The extended panic index in Model 3 behaves quite differently, with positive effects for all weekdays relative to the weekend. The implication is that workers think more about unemployment during the workweek.

Table 5. Additional Terms for Models of COVID-19 Panic

\begin{tabular}{ccccc} 
Models of $\ln \left(\right.$ panic $\left._{c t}\right):$ & Model 1 & Model 2 & Model 3 & Model 4 \\
& & & & \\
\hline & & & & \\
Day of the Week Effect: & & & & \\
Monday & -0.023 & -0.021 & 0.055 & -0.016 \\
& $(0.011)$ & $(0.010)$ & $(0.011)$ & $(0.011)$ \\
Tuesday & -0.026 & -0.025 & 0.029 & -0.023 \\
& $(0.011)$ & $(0.011)$ & $(0.011)$ & $(0.011)$ \\
Wednesday & -0.018 & -0.021 & 0.017 & -0.018 \\
Thursday & $(0.010)$ & $(0.011)$ & $(0.010)$ & $(0.011)$ \\
Friday & 0.021 & 0.010 & 0.047 & 0.012 \\
Saturday & $(0.011)$ & $(0.011)$ & $(0.010)$ & $(0.011)$ \\
& 0.030 & 0.015 & 0.028 & 0.017 \\
Constant & $(0.011)$ & $(0.011)$ & $(0.010)$ & $(0.010)$ \\
& 0.041 & 0.032 & -0.001 & 0.032 \\
& $(0.011)$ & $(0.011)$ & $(0.010)$ & $(0.010)$ \\
& & & & \\
& -0.807 & -1.012 & -0.876 & -0.846 \\
& $(0.036)$ & $(0.040)$ & $(0.037)$ & $(0.046)$ \\
& & & &
\end{tabular}

Note: This table contains the results for supplementary terms that were excluded from Table 2 and Table 3 for brevity. Standard errors are in parenthesis.

Finally, Table 6 presents estimates of the models of the log error variance in Models 1 and 2 . These are obtained by regressing the log squared residuals from first stage models $\ln \left(\hat{e}_{c t}^{2}\right)$ on the complete vector of regressors. The results are discussed in Section 4.2. Using these results, Models 1 and 2 are estimated by weighted least squares (WLS). The procedure entails: extracting $\hat{e}_{c t}$ from a first stage fixed-effects regression, regressing $\ln \left(\hat{e}_{c t}^{2}\right)$ on the independent variables, obtaining the fitted values $\hat{u}_{c t}$, and then using $1 / \sqrt{e^{\hat{u}_{c t}}}$ as the weights in the WLS regression. Models 3 and 4 are estimated in the same way, but we do not present the variance regression for these models. 
Table 6. Regression Models for the Error Variance

\begin{tabular}{|c|c|c|c|c|}
\hline \multirow{2}{*}{ Models of $\ln \left(\hat{e}_{c t}^{2}\right)$ : } & \multicolumn{2}{|c|}{ Model 1} & \multicolumn{2}{|c|}{ Model 2} \\
\hline & $\beta$ & S.E. & $\beta$ & S.E. \\
\hline \multicolumn{5}{|l|}{ Internal Restrictions: } \\
\hline$\Delta$ Internal $_{c t}$ & 0.222 & 0.129 & -0.343 & 0.258 \\
\hline$\Delta$ Internal $_{c t-1}$ & 0.283 & 0.130 & 0.150 & 0.260 \\
\hline$\Delta$ Internal $_{f t}$ & -0.008 & 0.236 & 0.131 & 0.813 \\
\hline$\Delta$ Internal $_{f t-1}$ & & & 1.164 & 0.998 \\
\hline$\Delta$ Internal $_{c t} *$ Internal $_{f t}$ & & & 0.154 & 0.118 \\
\hline$\Delta$ Internal $_{c t-1} *$ Internal $_{f t-1}$ & & & -0.086 & 0.119 \\
\hline \multicolumn{5}{|l|}{ Stimulus Announcements: } \\
\hline$\Delta$ Stimulus $_{c t}$ & -0.366 & 0.228 & 0.041 & 0.416 \\
\hline$\Delta$ Stimulus $_{c t-1}$ & 0.110 & 0.229 & 0.259 & 0.416 \\
\hline$\Delta$ Stimulus $_{f t}$ & & & 1.733 & 1.275 \\
\hline$\Delta$ Stimulus $_{f-1}$ & & & -0.760 & 1.232 \\
\hline$\Delta$ Stimulus $_{c t} *$ Stimulus $_{f t}$ & & & -0.415 & 0.353 \\
\hline$\Delta$ Stimulus $_{c t-1} *$ Stimulus $_{f t-1}$ & & & -0.391 & 0.353 \\
\hline \multicolumn{5}{|l|}{ Travel Restrictions: } \\
\hline$\Delta$ Travel $_{c t}$ & 0.077 & 0.066 & 0.065 & 0.148 \\
\hline$\Delta$ Travel $_{c t-1}$ & 0.075 & 0.066 & 0.334 & 0.148 \\
\hline$\Delta$ Travel $_{f t}$ & & & -0.912 & 0.449 \\
\hline$\Delta$ Travel $_{f t-1}$ & & & -0.055 & 0.379 \\
\hline$\Delta$ Travel $_{c t} *$ Travel $_{f t}$ & & & 0.002 & 0.037 \\
\hline$\Delta$ Travel $_{c t-1} *$ Travel $_{f t-1}$ & & & -0.053 & 0.037 \\
\hline \multicolumn{5}{|l|}{ Domestic COVID-19 Cases: } \\
\hline$\Delta \ln \left(C_{c t}\right)$ & 2.134 & 0.598 & 1.458 & 0.638 \\
\hline$\Delta C_{c t}$ & -0.022 & 0.023 & -0.025 & 0.021 \\
\hline$\Delta C_{c t} * \Delta \ln \left(C_{c t}\right)$ & & & -0.125 & 0.209 \\
\hline$\Delta \ln \left(C_{c t}^{*}\right)$ & 1.092 & 0.827 & -0.374 & 0.778 \\
\hline$\Delta C_{c t}^{*}$ & -0.039 & 0.060 & -0.076 & 0.053 \\
\hline \multicolumn{5}{|l|}{ International COVID-19 Cases: } \\
\hline$\Delta \ln \left(C_{f t}\right)$ & & & -3.791 & 1.266 \\
\hline$\Delta C_{f t}$ & & & -0.048 & 0.062 \\
\hline$\Delta C_{C h i n a, t}$ & & & -0.004 & 0.030 \\
\hline$\Delta C_{C h i n a, t} * A_{s i a}$ & & & 0.097 & 0.076 \\
\hline \multicolumn{5}{|l|}{ Autoregressive Terms: } \\
\hline $\ln \left(\right.$ panic $\left._{i, t-1}\right)$ & 0.116 & 0.125 & 0.503 & 0.112 \\
\hline $\ln \left(\right.$ panic $\left._{i, t-2}\right)$ & -0.093 & 0.124 & 0.119 & 0.111 \\
\hline
\end{tabular}

Diagnostics: $\begin{array}{lll}R^{2} & 0.014 & 0.017\end{array}$

Note: This table presents the fixed effects models of $\ln \left(\hat{e}_{c t}^{2}\right)$ used to weight the WLS regressions in Table 2. The day of week effects are excluded from the table for the sake of brevity. 


\section{APPENDIX C: TRANSLATING THE ENGLISH SEARCH TERMS}

Table 7 contains an extensive list of translations of the English keywords that we used to derive the panic index. The priority was to obtain translations that were being actively searched in the relevant countries over the last four months. If a literal or strict translation did not yield sufficient google search activity, a loose translation or even a translation of a related concept that had more activity would be chosen instead (e.g. a translation of 'stockpiling' instead of 'hoarding'). In our acknowledgements we mention the native speakers that helped us by looking at the translations and suggesting possible alternatives. Translations for the remaining languages, which are Russian, Vietnamese, Arabic, Persian, Turkish, Hindi, Greek, and Thai can be found in the files of the online replication package released alongside this article. 
Consumer Panic in the COVID-19 Pandemic

Table 7. Example Translations of the English Google Search Terms

\begin{tabular}{|c|c|c|c|c|c|c|c|}
\hline English Keywords: & $\begin{array}{l}\text { Toilet } \\
\text { Paper }\end{array}$ & Panic & $\begin{array}{l}\text { Panic } \\
\text { Buying }\end{array}$ & Hoarding & $\begin{array}{l}\text { Supermar- } \\
\text { ket }\end{array}$ & Recession & $\begin{array}{l}\text { Unemploy- } \\
\text { ment }\end{array}$ \\
\hline French & $\begin{array}{l}\text { papier } \\
\text { toilette }\end{array}$ & panique & pénurie & palissade & $\begin{array}{l}\text { super- } \\
\text { marché }\end{array}$ & récession & chômage \\
\hline German & $\begin{array}{l}\text { toiletten- } \\
\text { papier }\end{array}$ & panik & $\begin{array}{c}\text { ham- } \\
\text { sterkäufe }\end{array}$ & Vorrat & $\begin{array}{l}\text { super- } \\
\text { markt }\end{array}$ & rezession & $\begin{array}{l}\text { arbeit- } \\
\text { slosigkeit }\end{array}$ \\
\hline Spanish & $\begin{array}{c}\text { papel } \\
\text { higiénico }\end{array}$ & $\begin{array}{l}\text { panico }+ \\
\text { incer- } \\
\text { tidumbre }\end{array}$ & $\begin{array}{c}\text { desabastec- } \\
\text { imiento }+ \\
\text { compras de } \\
\text { panico }\end{array}$ & acopio & $\begin{array}{l}\text { supermer- } \\
\text { cado }\end{array}$ & recesión & desempleo \\
\hline Portuguese & $\begin{array}{c}\text { papel } \\
\text { higienico }\end{array}$ & histeria & escassez & $\begin{array}{l}\text { aglomer- } \\
\text { ação }\end{array}$ & $\begin{array}{l}\text { supermer- } \\
\text { cado }\end{array}$ & recessão & $\begin{array}{c}\text { desem- } \\
\text { prego }\end{array}$ \\
\hline Italian & $\begin{array}{c}\text { carta } \\
\text { igienica }\end{array}$ & panico & $\begin{array}{l}\text { coron- } \\
\text { avirus } \\
\text { supermer- } \\
\text { cato }\end{array}$ & scorta & $\begin{array}{l}\text { supermer- } \\
\text { cato }\end{array}$ & recessione & $\begin{array}{l}\text { disoccu- } \\
\text { pazione }\end{array}$ \\
\hline Dutch & $\begin{array}{l}\text { toiletpa- } \\
\text { pier }\end{array}$ & paniek & hamsteren & voorraad & $\begin{array}{l}\text { super- } \\
\text { markt }\end{array}$ & recessie & $\begin{array}{l}\text { werk- } \\
\text { loosheid }\end{array}$ \\
\hline Polish & $\begin{array}{l}\text { papier } \\
\text { toaletowy }\end{array}$ & panika & $\begin{array}{l}\text { skład- } \\
\text { owanie }\end{array}$ & skarb & & recesja & bezrobocie \\
\hline Danish & toiletpapir & panik & lager & hamstring & $\begin{array}{l}\text { super- } \\
\text { marked }\end{array}$ & & $\begin{array}{l}\text { arbejd- } \\
\text { sløshed }\end{array}$ \\
\hline Finnish & $\begin{array}{l}\text { vessapa- } \\
\text { peri }\end{array}$ & paniikki & hamstraus & aita & & lama & työttömyys \\
\hline Swedish & $\begin{array}{l}\text { toalettpap- } \\
\text { per }\end{array}$ & panik & hamstra & hamstring & mataffär & $\begin{array}{l}\text { lågkon- } \\
\text { junktur }\end{array}$ & $\begin{array}{l}\text { arbet- } \\
\text { slöshet }\end{array}$ \\
\hline Norwegian & $\begin{array}{l}\text { toalettpa- } \\
\text { pir }\end{array}$ & panikk & hamstre & samler & $\begin{array}{l}\text { dagligvare- } \\
\text { butikk }\end{array}$ & resesjon & $\begin{array}{l}\text { arbeid- } \\
\text { sledighet }\end{array}$ \\
\hline Japanese & $\begin{array}{c}\text { トイレッ } \\
\text { トペーパ } \\
\text { - }\end{array}$ & パニック & 買いだめ & 買いだめ & $\begin{array}{c}\text { スーパー } \\
\text { マーケッ } \\
\text { ト }\end{array}$ & 不況 & 失業 \\
\hline Korean & 화장지 & 공황 & 사재기 & 비축 & 마트 & 경기 & 실업 \\
\hline Chinese & 衛生紙 & 恐慌 & 搶購 & 囤 & 超級市場 & 經濟蕭條 & 失業 \\
\hline
\end{tabular}

